\title{
Optimisation and Evaluation of Antibacterial Topical Preparation from Malaysian Kelulut Honey using Guar Gum as Polymeric Agent
}

\author{
Mohd Amir Shahlan Mohd-Aspar ${ }^{1}$, Raihana Zahirah Edros ${ }^{1 *}$ and \\ Norul Amilin Hamzah ${ }^{2}$
}

${ }^{1}$ Faculty of Chemical and Process Engineering Technology, Universiti Malaysia Pahang, Lebuhraya Tun Razak, 26300 Kuantan, Pahang, Malaysia

${ }^{2}$ The Pathology and Laboratory Medicine Department, International Islamic University Malaysia (IIUM) Medical Centre, 25200 Kuantan, Pahang, Malaysia

\begin{abstract}
The study aims to formulate and optimise topical antibacterial preparation using Malaysian kelulut honey as the active ingredient and guar gum as the polymeric agent. Response surface methodology (RSM) was used to optimise the preparation. The acidity, honey concentration, and guar gum concentration were the independent variables. Meanwhile, the zone of inhibitions on Staphylococcus aureus ATCC6538 and Escherichia coli ATCC8739 were the response variables. The optimal preparation was evaluated on its physicochemical properties, viscosity, antibacterial efficacy, and stability. The antibacterial efficacy of the optimal preparation was compared to the commercial antibacterial gel (MediHoney ${ }^{\mathrm{TM}}$, Comvita). The optimal preparation was formulated at $\mathrm{pH} 3.5$, honey concentration of $90 \%$ $(\mathrm{w} / \mathrm{v})$, and guar gum concentration of $1.5 \%(\mathrm{w} / \mathrm{v})$. The inhibition zones measured on $S$. aureus ATCC6538 was $16.2 \mathrm{~mm}$ and E. coli ATCC8739 was $15.8 \mathrm{~mm}$, respectively. The optimal preparation showed good physicochemical properties and effective antibacterial properties. However, the viscosity of the preparation was reduced by more than $50 \%$ during the six months of the stability study. Guar gum is a potential polymeric agent in preparing kelulut as topical preparation with effective

ARTICLE INFO

Article history:

Received: 20 July 2020

Accepted: 07 December 2020

Published: 22 January 2021

DOI: https://doi.org/10.47836/pjst.29.1.30

antibacterial properties. Consideration of additional stabilising or preservative agent is recommended to overcome the reduction of viscosity over time.
\end{abstract}

E-mail addresses:

amirshahlan@ump.edu.my (Mohd Amir Shahlan Mohd-Aspar) rzahirah@ump.edu.my (Raihana Zahirah Edros)

amilin@iium.edu.my (Norul Amilin Hamzah)

* Corresponding author
Keywords: Antibacterial properties, guar gum, Malaysian kelulut, topical preparation 


\section{INTRODUCTION}

Honey has been successfully applied as a topical preparation in the treatment of wound infection. Other than antibacterial properties, other additional characteristics of honey such as non-irritant, non-toxic, self-sterile, nutritive, and easy application (Boukraâ, 2014; Ismail, 2016) enhance its potential of being effectively utilised as a topical agent. Among various types of honey, manuka is most commonly used as an agent to prevent bacterial infection. Manuka, with its Unique Manuka Factor (UMF) of 10+ and above, is documented as the medical-grade honey used in clinical application as an antibacterial agent (Tan et al., 2009). In Malaysia, several types of honey are actively harvested, including tualang, kelulut, and acacia. These types of honey were studied and found to possess potent antibacterial properties, including bacteriostatic and bactericidal effects (Jalil et al., 2017; Tuksitha et al., 2018; Yaacob et al., 2018). Interestingly, kelulut was revealed to have higher antibacterial properties comparable to manuka honey for preventing the growth of common pathogenic bacterial species, such as Pseudomonas aeruginosa (Mohd-Aspar \& Edros, 2019). Although described to possess potent antibacterial properties, the report of kelulut honey utilisation as an agent to prevent bacterial infection is lacking.

Honey harvested from the tropical rainforest in Malaysia contained high moisture content (exceeding 20\%), causing it to be less viscous, diluted, and unsuitable to be directly applied without improving its rheological properties. The honey could not remain on the site of action for as long as necessary and maintain a concentration within an effective range to promote bacteriostatic and bactericidal effects (El-Kased et al., 2017; Zhu et al., 2019). In this study, the rheological properties of Malaysian honey have been improved for the topical application using natural polymeric agents, i.e., guar gum.

The objective of this study was to evaluate the potential development of a topical preparation from Malaysian kelulut honey with the employment of guar gum as the polymeric agent. To maximise the effect on the prevention of bacterial growth, the preparation was optimised by considering the most effective $\mathrm{pH}$, honey concentration, and polymeric agent concentration used. The optimisation was performed through response surface methodology (RSM). The optimal preparation was evaluated on its physicochemical properties, antibacterial efficacy, and stability to confirm its quality. As for antibacterial efficacy, the commercially available antibacterial gel (MediHoney ${ }^{\mathrm{TM}}$ ) was used as a basis for comparison.

\section{MATERIALS AND METHODS}

\section{Honey Samples}

Kelulut honey sample was obtained from a local apiarist and aseptically stored in sterile bottles. The honey was harvested in March 2016 from the farm located at Guar Batu Hitam, Kodiang, Kedah, Malaysia. Information on the collected honey was recorded in 
the Certificate of Analysis (CoA) obtained during the purchase of the honey, accredited by the authorised institution, the Malaysian Agriculture Research and Development Institute (MARDI). An additional assay using the RapidRaw ${ }^{\mathrm{TM}}$ method developed by the Malaysia Genome Institute (MGI) to confirm the purity of the honey sample was included. The honey was stored in sterile glass bottles for experimental work and kept away from direct sunlight at room temperature in a dark plastic container.

\section{Materials and Reagents}

The guar gum was purchased from Sigma, USA. Sodium benzoate and triethanolamine (TEA) were purchased from Bendosen, Malaysia.

\section{Bacteria}

The study had employed 8 standard strains and 14 clinically isolated strains of common wound-infecting bacteria. The eight standard bacterial strains obtained from the American Type Culture Collection (ATCC, USA) were kindly supplied by the Department of Pathology and Laboratory Medicine, International Islamic University Malaysia Medical Centre (IIUMMC) and Central Laboratory, Universiti Malaysia Pahang (UMP). The strains included three Gram-positive bacteria, i.e., Staphylococcus aureus ATCC 6538, Streptococcus pyogenes ATCC 19615, and Enterococcus faecalis ATCC 29212, and five Gram-negative bacteria, i.e., Escherichia coli ATCC 8739, Pseudomonas aeruginosa ATCC 9027, Salmonella typhimurium ATCC 14028, Proteus mirabilis ATCC 12453, and Klebsiella pneumoniae ATCC BAA 1144. The 14 clinically isolated bacteria were primarily obtained from the Department of Pathology and Laboratory Medicine, International Islamic University Malaysia Medical Centre (IIUMMC). These included five Gram-positive bacteria, i.e., S. aureus, Staphylococcus hominis, Staphylococcus haemolyticus, S. pyogenes, and Streptococcus agalactiae and another nine Gram-negative bacteria, i.e., E. coli, P. aeruginosa, Salmonella sp., P. mirabilis, Proteus vulgaris, K. pneumoniae, Acinetobacter baumannii, Enterococcus cloacae, and Enterococcus aerogenes. The bacteria were recultured in nutrient or soy agar and incubated at $37^{\circ} \mathrm{C}$ for $24 \mathrm{~h}$, known as primary culture.

The working bacterial culture was prepared by inoculating a loop of primary culture into sterile screw-capped test tubes containing $10 \mathrm{~mL}$ of broth and incubated in a shaking incubator for $24 \mathrm{~h}$ at $37^{\circ} \mathrm{C}$ and rotational speed of $150 \mathrm{rpm}$. The prepared working bacteria cultures were adjusted to $0.5 \mathrm{McF}$ arland standard, equivalent to $1.5 \times 10^{8} \mathrm{CFU} / \mathrm{mL}$. They were prepared based on optical density by diluting the working bacteria into the fresh sterile broth and adjusted to be in the absorbance range of 0.08 to 0.13 (Franklin et al., 2012). The absorbance of the prepared cultures was measured using Ultraviolet-Visible Spectrophotometer UV-1800 (Shimadzu, Japan) at the reference wavelength of $600 \mathrm{~nm}$. 


\section{Preparation of the Antibacterial Topical Preparation}

The preparation of kelulut honey was performed by dissolving the desired amount of guar gum in sterile deionised water with continuous stirring for $1 \mathrm{~h}$ until the polymer was completely soaked in water. This step was followed by the addition of $0.02 \%(\mathrm{w} / \mathrm{v})$ sodium benzoate (Bendosen, Malaysia) as a preservative in the preparation. The desired amount of honey was added to the mixture with continuous stirring for another $30 \mathrm{~min}$ until the honey was dissolved. The final volume of each preparation was set to $100 \mathrm{~mL}$ by adding sterile deionised water. The preparation was kept in a sterile, wide-mouth glass container covered with a lid and stored at $28^{\circ} \mathrm{C}$ for $24 \mathrm{~h}$ for complete swelling.

\section{Optimisation of the Preparation}

The preparation was set at its optimum antibacterial properties through the RSM. The experimental domain is defined as the antibacterial properties of the preparation. The three independent variables are acidity, honey concentrations $(\%, w / v)$, and guar gum concentrations $(\%, \mathrm{w} / \mathrm{v})$, designated as $X_{1}, X_{2}$, and $X_{3}$, respectively. The inhibition zone (mm) on S. aureus ATCC 6538 and E. coli ATCC 8739 were collected as the response variables designated as $Y_{1}$ and $Y_{2}$, respectively. $S$. aureus and E. coli were selected because these species were commonly isolated from infected wounds and had various mechanisms of resistance towards antibacterial agents (Brudzynski \& Sjaarda, 2014; Peacock \& Paterson, 2015).

In each of the independent variables $X_{1}, X_{2}$, and $X_{3}$, the optimum parameters were determined within the range set during the optimisation work. The details of the values set during the optimisation process are tabulated in Table 1 . The low and high levels were set between $\mathrm{pH}$ of 3.5 and 6.5 for acidity $\left(X_{1}\right), 50 \%$ and $90 \%(\mathrm{w} / \mathrm{v})$ for honey concentration $\left(X_{2}\right)$, and $1.0 \%$ and $2.0 \%(\mathrm{w} / \mathrm{v})$ for the guar gum concentration $\left(X_{3}\right)$, respectively. The axial points were obtained based on the range defined for low and high levels which used to obtain an efficient estimation of the quadratic model (Morshedi \& Akbarian, 2014; Wang et al., 2011).

Table 1

Actual values of the independent variables for the optimisation process

\begin{tabular}{lccccc}
\hline \multicolumn{1}{c}{ Factor } & $\begin{array}{c}\text { Low-level } \\
\text { axial point }\end{array}$ & $\begin{array}{c}\text { Low-level } \\
\text { factorial }\end{array}$ & Centre point & $\begin{array}{c}\text { High-level } \\
\text { factorial }\end{array}$ & $\begin{array}{c}\text { High-level } \\
\text { axial point }\end{array}$ \\
\hline $\begin{array}{l}X_{1}: \mathrm{pH} \\
X_{2}: \text { Honey } \\
\begin{array}{l}\text { concentration } \\
(\%, \mathrm{w} / \mathrm{v})\end{array}\end{array}$ & 2.48 & 3.50 & 5.00 & 6.50 & 7.52 \\
$\begin{array}{l}X_{3}: \text { Guar gum } \\
\text { concentration } \\
(\%, \mathrm{w} / \mathrm{v})\end{array}$ & 36.36 & 50.00 & 75.00 & 90.00 & 103.64 \\
\hline
\end{tabular}


In this study, the RSM based on central composite design (CCD) was used to optimise the antibacterial properties of the preparation. According to the $\mathrm{CCD}$, the total number of experimental combinations is based on Equation 1 below (Anitha \& Pandey, 2016; Shekar et al., 2014):

$$
2^{k}+2 k+n_{0}
$$

Where $\mathrm{k}$ is the number of independent variables and $\mathrm{n}_{0}$ is the number of repetitions of the experiments at the central points. In this study, three independent variables were involved $(\mathrm{k}=3)$ with five replicates at the centre points $\left(\mathrm{n}_{0}=5\right)$, leading to a total of nineteen runs. The details of the 19 experimental runs are tabulated in Table 2.

The Design of Experts Software (DOE version, 7.1.3, STAT-EASE Inc., Minneapolis, USA) was used for Analysis of Variance (ANOVA), regression, and graphical analyses of the data obtained. The regression model, three-dimensional response graph, and desirability function to get the optimum combinations of independent variables were plotted using the same software. In ANOVA, the analysis included overall model significance, correlation coefficient $(\mathrm{R})$, and determination coefficient $\left(\mathrm{R}^{2}\right)$ that measure the goodness of fit of the regression model.

Table 2

Experimental design of the central composite design

\begin{tabular}{cccc}
\hline \multirow{2}{*}{ Run } & \multicolumn{3}{c}{ Factor } \\
\cline { 2 - 4 } & $X_{1}: \mathrm{pH}$ & $X_{2}:$ Honey concentration $(\%, \mathrm{w} / \mathrm{v})$ & $X_{3}$ : Guar gum concentration $(\%, \mathrm{w} / \mathrm{v})$ \\
\hline 1 & 3.50 & 50.00 & 1.00 \\
3 & 6.50 & 50.00 & 1.00 \\
4 & 3.50 & 90.00 & 1.00 \\
5 & 6.50 & 90.00 & 1.00 \\
6 & 3.50 & 50.00 & 2.00 \\
7 & 6.50 & 50.00 & 2.00 \\
8 & 3.50 & 90.00 & 2.00 \\
9 & 6.50 & 90.00 & 2.00 \\
10 & 2.48 & 70.00 & 1.50 \\
11 & 7.52 & 70.00 & 1.50 \\
12 & 5.00 & 36.36 & 1.50 \\
13 & 5.00 & 103.64 & 1.50 \\
14 & 5.00 & 70.00 & 0.66 \\
15 & 5.00 & 70.00 & 2.34 \\
16 & 5.00 & 70.00 & 1.50 \\
17 & 5.00 & 70.00 & 1.50 \\
18 & 5.00 & 70.00 & 1.50 \\
19 & 5.00 & 70.00 & 1.50 \\
\hline
\end{tabular}




\section{Measurement of Inhibition Zone}

This assay was used during the optimisation process and after optimisation of the preparation process. In this assay, soy agar was used to grow E. faecalis and S. pyogenes, while nutrient agar was used to grow the remaining bacteria, i.e., S. aureus, E. coli, $P$. aeruginosa, S. typhimurium, $P$. mirabilis, and $K$. pneumonia. The nutrient and soy agar were prepared by dissolving $23 \mathrm{~g}$ and $40 \mathrm{~g}$ of agar powder to $1 \mathrm{~L}$ of distilled water and later autoclaved at the pressure of $100 \mathrm{kPa}$ and temperature of $121^{\circ} \mathrm{C}$ for $20 \mathrm{~min}$. The agars were allowed to cool down slightly and was poured into $90 \mathrm{~mm} \times 15 \mathrm{~mm}$ (Brandon ${ }^{\mathrm{TM}}$, Malaysia) Petri dishes.

The working bacterial culture, which was adjusted to $0.5 \mathrm{McF}$ arland bacteria concentration, was prepared. A volume of $100 \mu \mathrm{L}$ of the adjusted $0.5 \mathrm{McF}$ arland culture was spread onto the agar using the pour plate technique. Upon inoculation, $6 \mathrm{~mm}$ diameter wells were cut on the agar surface. The plate was divided into four quadrants, and a single well was created in each quadrant to contain $80 \mu \mathrm{L}$ of the preparation. The plates were incubated at $37^{\circ} \mathrm{C}$ for $24 \mathrm{~h}$. The inhibition zones diameters were measured in millimetres $(\mathrm{mm})$, based on the diameter of the circles formed around the tested well areas in which the bacterial colonies did not grow. This diameter is inclusive of the $6 \mathrm{~mm}$ well diameter that was used to occupy the tested preparation. Each test was carried out in triplicate, and the average values were calculated.

Based on the inhibition zones measured, the sensitivity of bacteria towards the preparation was categorised as not sensitive, sensitive, very sensitive, and extremely sensitive, as previously described (Moussa et al., 2012). The not sensitive category was denoted by the diameter of inhibition zone of lower than $8 \mathrm{~mm}$, sensitive for the diameter between 8 to $14 \mathrm{~mm}$, very sensitive for the diameter between 15 to $19 \mathrm{~mm}$, and extremely sensitive for the diameter of $20 \mathrm{~mm}$ and above.

\section{Evaluation of the Optimal Preparation}

The optimal preparation resulting from the optimisation process was evaluated in terms of physicochemical properties, antibacterial efficacy, and stability. This is essential to decide on adequate and reliable preparation.

\section{Physicochemical Properties}

The physicochemical properties of the optimal preparation were evaluated in terms of physical appearance, colour, homogeneity, grittiness, lump formation, viscosity, and $\mathrm{pH}$. The viscosity was measured using Viscometer VL210001 (Fungilab, Spain), spindle number R5, at 100 rotations per min. Meanwhile, the $\mathrm{pH}$ was measured using the $\mathrm{pH}$ meter SevenCompact ${ }^{\mathrm{TM}}$ (Mettler Toledo, USA). 


\section{Centrifugation Test}

The centrifugation test was performed using a refrigerated centrifuge 5810R (Eppendorf, Germany), as previously described by Dantas et al. (2016). It was performed by adding $10 \mathrm{~g}$ of the preparation in a tapered test tube and was subjected to a cycle of $151 \mathrm{~g}$ for 30 $\min$ at $25^{\circ} \mathrm{C}$.

\section{Antibacterial Efficacy}

The antibacterial efficacy of the optimal preparation was evaluated for its inhibition effect and bactericidal effect. For both evaluations, the experiments were performed on 22 bacterial species, including 8 standard strains and 14 clinical strains, as previously listed.

Measurement of Inhibition Zone. Prior to investigating the potency to inhibit bacterial growth, a study was conducted to measure the inhibition zone of bacterial strains when exposed to the preparation. This was performed qualitatively using the agar well diffusion assay, as previously described, to gain an understanding of the sensitivity of bacteria towards the preparation (Moussa et al., 2012; Sherlock et al., 2010). The diameters of the inhibition zone were measured in mm, including the diameter of the well created. Each test was carried out in triplicate, and the average values were calculated. The commercially available topical preparation formulated using manuka honey (MediHoney ${ }^{\mathrm{TM}}$ ) was used as the basis of comparison.

Bactericidal Effect. The bactericidal effect of the optimal preparation was determined using a tube dilution method, which was adapted from a previous antibacterial study (Shagana $\&$ Geetha, 2017). An equal volume of $0.5 \mathrm{~mL}$ of the preparation was mixed with $0.5 \mathrm{~mL}$ of freshly prepared broth in a screw cap tube (Jain et al., 2016; Shagana \& Geetha, 2017). Then, a loopful of the test organism adjusted to $0.5 \mathrm{McF}$ arland was transferred into the tube (Dewanjee et al., 2008). A tube containing $1 \mathrm{~mL}$ of broth and seeded with the test organism was used as a control. The prepared tubes were then incubated in the incubator shaker at $37^{\circ} \mathrm{C}$ and a rotational speed of $150 \mathrm{rpm}$ for $24 \mathrm{~h}$. After overnight incubation, a loopful suspension was suspended and inoculated onto freshly prepared Trypticase Soy Agar (TSA) using the streak plate method. Then, the plate was incubated for another 24 $\mathrm{h}$ in $37^{\circ} \mathrm{C}$ before being observed for bacterial growth. A plate with no visible bacterial growth (indicated by the formation of the bacterial colony) was considered to possess a bactericidal effect. In contrast, the plate with visible bacterial colony formation was considered to have no bactericidal effect. 


\section{Stability Study}

Evaluation of the stability of the optimal preparation was adapted from previous studies (Chen et al., 2016; Dantas et al., 2016; Majumdar et al., 2018) with slight modification. The preparation was kept in glass containers and stored for long-term and accelerated conditions, i.e., at $25^{\circ} \mathrm{C} \pm 2 / 60 \% \pm 5$ relative humidity $(\mathrm{RH})$ and $40^{\circ} \mathrm{C} \pm 2 / 75 \% \pm 5 \mathrm{RH}$, respectively, for 6 months and evaluated at $0,1,2,3$, and 6 months. The storage conditions were set according to the International Council of Harmonisation of Technical Requirement for Pharmaceuticals for Human Use (ICH) guideline (World Health Organisation, 2018). The evaluations were observed based on the colour, $\mathrm{pH}$, homogeneity, viscosity, and antibacterial efficacy, which were conducted similar to the procedures described in the previous sections. In the measurement of the inhibition zone and bactericidal effect, three Gram-positive strains, i.e., S. aureus ATCC 6538, E. faecalis ATCC, and S. pyogenes; and three Gram-negative strains, i.e., E. coli ATCC 8739, K. pneumonia, and E. aerogenes were considered.

\section{RESULTS AND DISCUSSION}

\section{Optimisation of the Antibacterial Topical Preparation}

A total of 19 runs were generated from RSM with different combination levels of $\mathrm{pH}$, the concentration of honey, and the concentration of guar gum. The observed responses from each run are tabulated in Table 3.

Based on the findings, the inhibition zones measured ranged from $7.8 \pm 0.00 \mathrm{~mm}$ to $14.6 \pm 0.58 \mathrm{~mm}$ on $S$. aureus and $8.0 \pm 0.58 \mathrm{~mm}$ to $14.5 \pm 0.50 \mathrm{~mm}$ on E. coli. The largest zones of inhibition of $14.6 \pm 0.58 \mathrm{~mm}$ and $14.5 \pm 0.50 \mathrm{~mm}$ were measured on $S$. aureus and $E$. coli, respectively, in run number 9 . In contrast, the smallest zones of inhibition of $7.8 \pm 0.29 \mathrm{~mm}$ and $8.0 \pm 0.58 \mathrm{~mm}$ were measured on $S$. aureus and E. coli, respectively, in run number 4 .

The relationship between independent and response variables was determined through the application of multiple regression analysis on the experimental data to generate a second-order polynomial model. The generated models were described as Equation 2 and Equation 3 representing the analysis of data for $S$. aureus and E. coli, respectively.

$$
\begin{aligned}
& Y_{1}=9.13-2.09 X_{1}+0.51 X_{2}+0.12 X_{3}-0.11 X_{1} X_{2}+0.34 X_{1} X_{3}+ \\
& 0.31 X_{2} X_{3}+0.76 X_{1}^{2}+0.14 X_{2}^{2}+0.07 X_{3}^{2} \\
& Y_{2}=8.97-1.98 X_{1}+0.48 X_{2}-0.023 X_{3}-0.57 X_{1} X_{2}+0.25 X_{1} X_{3}+ \\
& 0.20 X_{2} X_{3}+0.96 X_{1}^{2}+0.17 X_{2}^{2}+0.15 X_{3}^{2}
\end{aligned}
$$


The effect of $\mathrm{pH}\left(X_{1}\right)$ is more prominent in both equations compared to the concentration of honey $\left(X_{2}\right)$ and guar gum concentration $\left(X_{3}\right)$. This is due to the coefficient of $X_{1}$ with the value of 2.09, which is 4-fold and 17-fold higher than the coefficient of $X_{2}$ and $X_{3}$, with values of 0.51 and 0.12 for Equation 2. This also applies to Equation 3 with a value of 1.98 for $X_{1}$, which is 4-fold and 86-fold higher compared to $X_{2}$ and $X_{3}$, with values of 0.48 and 0.023 , respectively.

The significant impact of each term in the second-order polynomial equation was evaluated through ANOVA, and the results are tabulated in Table 4. The degree of significance for every term in the equation, including linear $\left(X_{1}, X_{2}, X_{3}\right)$, quadratic $\left(X_{1}^{2}\right.$, $\left.X_{2}^{2}, X_{3}^{2}\right)$, and combination $\left(X_{1} X_{2}, X_{1} X_{3}\right.$ and $\left.X_{2} X_{3}\right)$ were analysed at $95 \%$ confident interval $(P$-value $<0.05)$ (Ammer et al., 2016; Madiha et al., 2017).

Among the linear terms, the effects of $\mathrm{pH}\left(X_{1}\right)$ and honey concentration $\left(X_{2}\right)$ on the inhibition zones were highly significant, as shown by their respective $P$-values, with $P_{X 1}$ $<0.0001$ and $P_{X 2}=0.0051$ for $S$. aureus, and $P_{X 1}<0.0001$ and $P_{X 2}=0.0067$ for E. coli. In contrast, guar gum concentration $\left(X_{3}\right)$ had an insignificant effect on the inhibition zones

Table 3

Responses for the experimental runs

\begin{tabular}{cccccc}
\hline \multirow{2}{*}{ Run } & \multicolumn{3}{c}{ Factor } & \multicolumn{2}{c}{ Response of inhibition zone $(\mathrm{mm})$} \\
\cline { 2 - 5 } & $X_{1}$ & $X_{2}$ & $X_{3}$ & S. aureus $\left(Y_{1}\right)$ & E. coli $\left(Y_{2}\right)$ \\
\hline 1 & 3.50 & 50.00 & 1.00 & $12.7 \pm 0.58$ & $12.3 \pm 1.04$ \\
2 & 6.50 & 50.00 & 1.00 & $7.8 \pm 0.29$ & $8.5 \pm 0.58$ \\
3 & 3.50 & 90.00 & 1.00 & $12.8 \pm 0.76$ & $13.7 \pm 0.00$ \\
4 & 6.50 & 90.00 & 1.00 & $7.8 \pm 0.29$ & $8.0 \pm 0.58$ \\
5 & 3.50 & 50.00 & 2.00 & $11.0 \pm 0.50$ & $10.7 \pm 0.58$ \\
6 & 6.50 & 50.00 & 2.00 & $7.8 \pm 0.00$ & $8.3 \pm 0.58$ \\
7 & 3.50 & 90.00 & 2.00 & $12.7 \pm 0.58$ & $13.3 \pm 0.29$ \\
8 & 6.50 & 90.00 & 2.00 & $8.7 \pm 0.58$ & $8.2 \pm 0.29$ \\
9 & 2.48 & 70.00 & 1.50 & $14.6 \pm 0.58$ & $14.5 \pm 0.50$ \\
10 & 7.52 & 70.00 & 1.50 & $7.8 \pm 0.00$ & $8.5 \pm 0.58$ \\
11 & 5.00 & 36.36 & 1.50 & $8.2 \pm 0.76$ & $8.3 \pm 0.29$ \\
12 & 5.00 & 103.64 & 1.50 & $10.7 \pm 0.58$ & $10.2 \pm 0.58$ \\
13 & 5.00 & 70.00 & 0.66 & $8.5 \pm 0.58$ & $8.7 \pm 0.58$ \\
14 & 5.00 & 70.00 & 2.34 & $10.0 \pm 0.00$ & $9.7 \pm 0.50$ \\
15 & 5.00 & 70.00 & 1.50 & $8.7 \pm 0.58$ & $8.5 \pm 0.58$ \\
16 & 5.00 & 70.00 & 1.50 & $9.7 \pm 0.58$ & $9.0 \pm 0.00$ \\
17 & 5.00 & 70.00 & 1.50 & $9.3 \pm 0.58$ & $9.3 \pm 0.58$ \\
18 & 5.00 & 70.00 & 1.50 & $9.0 \pm 0.00$ & $8.8 \pm 1.04$ \\
19 & 5.00 & 70.00 & 1.50 & $9.0 \pm 1.00$ & $9.3 \pm 0.58$ \\
\hline
\end{tabular}

The symbol \pm represents the standard deviation, which was calculated between three biological replicates. Student's t-test shows significant differences for the data collected $(P$-value $<0.05)$ 
Table 4

Analysis of variance (ANOVA) of the quadratic model

\begin{tabular}{lcccc}
\hline \multirow{2}{*}{ Factors } & \multicolumn{2}{c}{ Inhibition zone on $S$. aureus } & \multicolumn{2}{c}{ Inhibition zone on E. coli } \\
\cline { 2 - 5 } & $P$-value & Model term & $P$-value & Model term \\
\hline$X_{1}$ & $<0.0001$ & Significant & $<0.0001$ & Significant \\
$X_{2}$ & 0.0051 & Significant & 0.0067 & Significant \\
$X_{3}$ & 0.4100 & Not Significant & 0.8696 & Not Significant \\
$X_{1} X_{2}$ & 0.5468 & Not Significant & 0.0110 & Not Significant \\
$X_{1} X_{3}$ & 0.0931 & Not Significant & 0.1989 & Not Significant \\
$X_{2} X_{3}$ & 0.1160 & Not Significant & 0.2961 & Not Significant \\
$X_{1}{ }^{2}$ & 0.0004 & Significant & $<0.0001$ & Significant \\
$X_{2}{ }^{2}$ & 0.3332 & Not Significant & 0.2598 & Not Significant \\
$X_{3}{ }^{2}$ & 0.6233 & Not Significant & 0.3105 & Not Significant \\
Model & $<0.0001$ & Significant & $<0.0001$ & Significant \\
Lack of fit & 0.2028 & Not significant & 0.1413 & Not significant \\
\hline
\end{tabular}

Significant at $5 \%$ level $(P$-value $<0.05)$

for both $S$. aureus and $E$. coli, with $P_{X 3}=0.4100$ and $P_{X 3}=0.8696$, respectively. As for quadratic terms, only $X_{1}^{2}$ was significant for both $S$. aureus and E. coli, with $P_{X 1}{ }^{2}=0.0004$ for $S$. aureus and $P_{X 1}{ }^{2}<0.0001$ for E. coli. Meanwhile, $X_{2}^{2}$ and $X_{3}^{2}$ were insignificant with $P_{X 2}{ }^{2}=0.3332$ and $P_{X 3}{ }^{2}=0.6233$ for $S$. aureus, and $P_{X 2}{ }^{2}=0.2598$ and $P_{X 3}{ }^{2}=0.3105$ for E. coli. Meanwhile, none of the combination terms had a significant effect on the inhibition zones. The results suggest that $\mathrm{pH}$ and honey concentrations have a significant relationship with the inhibition zones, as a small variation in the values considerably altered the inhibition zone for both $S$. aureus and $E$. coli. The results are in agreement with previous studies in which $\mathrm{pH}$ and honey concentration influenced antibacterial properties of honey (Johnston et al., 2018; Kateel et al., 2018).

According to Table 4, results of the ANOVA demonstrated that the model was highly significant, with $P$-value $<0.0001$ for both $S$. aureus and $E$. coli, indicating that the polynomial models, as expressed by Equation 2 and Equation 3, provide a reliable description of the responses. In addition, the ANOVA also showed a statistically insignificant lack of fit with $P$-value $=0.2028$ and 0.1413 for $S$. aureus and $E$. coli, respectively, indicating an adequate prediction of responses by the model (Wang et al., 2011).

The coefficients of determination $\mathrm{R}^{2}=0.9691$ and 0.9689 , as described in Table 5, imply that the zone of inhibition is attributed to the given independent variables. The $\mathrm{R}^{2}$ values indicate that $97 \%$ of the total variation is explained by the model, and the remaining $3 \%$ of unexplained conditions is contributed by unknown factors. The adjusted determination coefficients (adjusted $\mathrm{R}^{2}=0.9697$ and 0.9689 ) are also high, indicating good accuracy and ability of the polynomial model to predict the response trend. It can be concluded that the second-order polynomial models are adequate to describe the inhibition 
Table 5

Coefficient of correlation $(R)$ and coefficient of determination $\left(R^{2}\right)$ of the quadratic model

\begin{tabular}{lcc}
\hline & Inhibition zone on $S$. aureus & Inhibition zone on E. coli \\
\hline $\mathrm{R}^{2}$ & 0.9691 & 0.9689 \\
Adjusted $\mathrm{R}^{2}$ & 0.9383 & 0.9379 \\
\hline
\end{tabular}

zone with the response to $\mathrm{pH}$, honey concentration, and guar gum concentration as the independent variables.

\section{Response Surface Analysis}

The interaction between independent variables; $X_{1} X_{2}, X_{1} X_{3}$, and $X_{2} X_{3}$, as indicated in Equation 2 and Equation 3, can be visualised using 3D response surface and 2D contour plots, as shown in Figure 1 for $S$. aureus ATCC 6538 and Figure 2 for E. coli ATCC 8739. These plots are important to illustrate the effects of independent variables and their interactions on the response variables.

Figure 1 (a) and Figure 2 (a) show the 3D plots and their corresponding contour plots, showing the effect of $\mathrm{pH}\left(X_{1}\right)$ and honey concentration $\left(X_{2}\right)$ on the inhibition zones of $S$. aureus and E. coli, while the concentration of guar gum $\left(X_{3}\right)$ was fixed at its middle level, which was $1.5 \%(\mathrm{w} / \mathrm{v})$. At $\mathrm{pH}$ between 3.5 and 6.5 , the concentration of honey was directly proportional to the inhibition zone for both $S$. aureus and E. coli regardless of the $\mathrm{pH}$ level. In contrast, the $\mathrm{pH}$ was inversely proportional to the inhibition zone at any concentration of honey between $50 \%$ and $90 \%(w / v)$. The analysis of Figure 1 (a) and Figure 2 (a) showed that the optimal $\mathrm{pH}$ was at the lowest $\mathrm{pH}$, i.e., at 3.5 and the honey concentration was at $90 \%(\mathrm{w} / \mathrm{v})$ due to the largest inhibition zone estimated at these conditions. The finding is congruent with a study that reported the effectiveness of acidity in preventing bacterial growth (El-Kased et al., 2017). The reason for larger inhibition zones at strong acidic $\mathrm{pH}$ compared to neutral $\mathrm{pH}$ could be due to the unbefitting bacterial growth condition, which required $\mathrm{pH}$ between 6.6 to 7.0 (Jones et al., 2015). Furthermore, the antimicrobial properties of compounds such as flavonoids and phenolic acids available in kelulut honey were reported to increase at lower pH (Sanchez-Maldonado et al., 2011). As for the concentration of honey, the increased diameter of the inhibition zone with an increased concentration of honey can be explained by the increase in antibacterial compounds, such as phenolic acids and flavonoids, which increased as the concentration of honey increased (Bakar et al., 2017; Tuksitha et al., 2018). In addition, the degree of sugar content naturally present in kelulut honey will also lead to a potential increase in osmotic pressure to inhibit the growth of bacteria (Dluya, 2016). These findings are similar to the previous study that found a higher inhibition zone in response to increments of honey concentration used in honey-based preparations (El-Kased et al., 2017). 
Figure 1 (b) and Figure 2 (b) depict the 3D plots and their corresponding contour plots showing the effects of $\mathrm{pH}\left(X_{1}\right)$ and guar gum concentration $\left(X_{3}\right)$ on inhibition zones of $S$. aureus and $E$. coli, while the honey concentration was fixed at its middle level, i.e., at $70 \%(\mathrm{w} / \mathrm{v})$. There was a lack of interaction between $\mathrm{pH}$ and guar gum concentration on the zones of inhibition. As the preparations were formulated with guar gum concentration between $1.0 \%$ and $2.0 \%(\mathrm{w} / \mathrm{v})$, the zones of inhibition remained unchanged for both $S$. aureus and E. coli, regardless of the variation in $\mathrm{pH}$ level. Similarly, as the $\mathrm{pH}$ was increased from 3.5 to 6.5 , the inhibition was decreased without being affected by guar

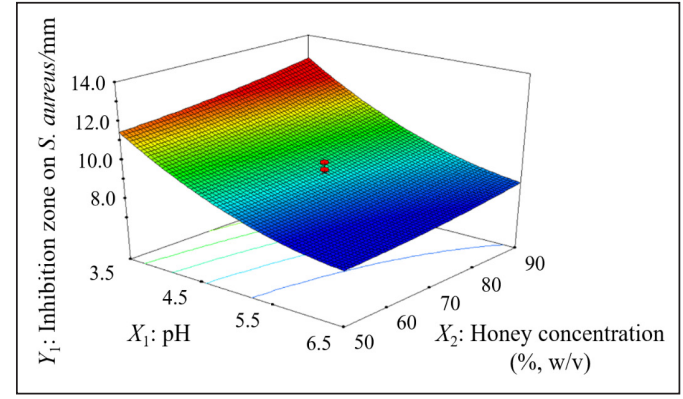

(a)

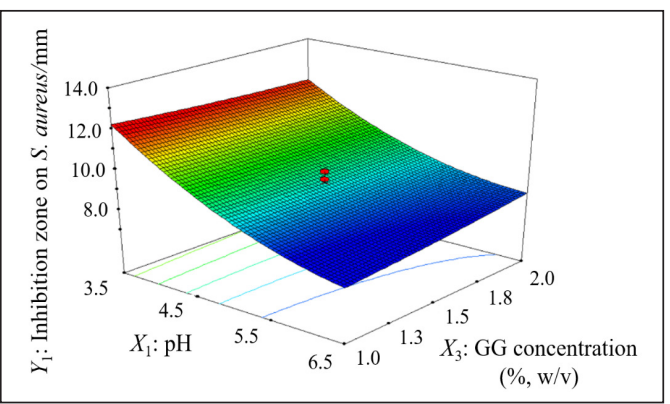

(b)

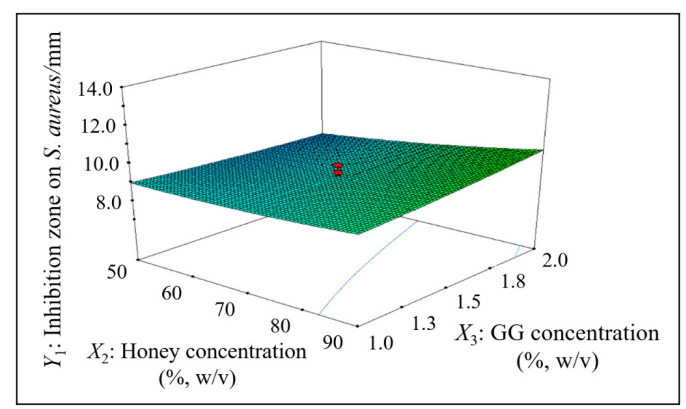

(c)

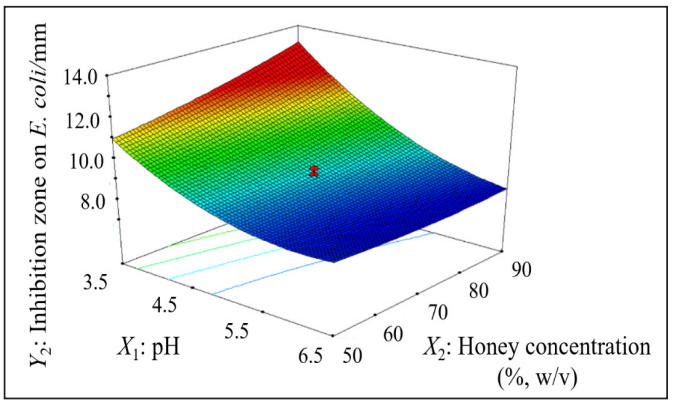

(a)

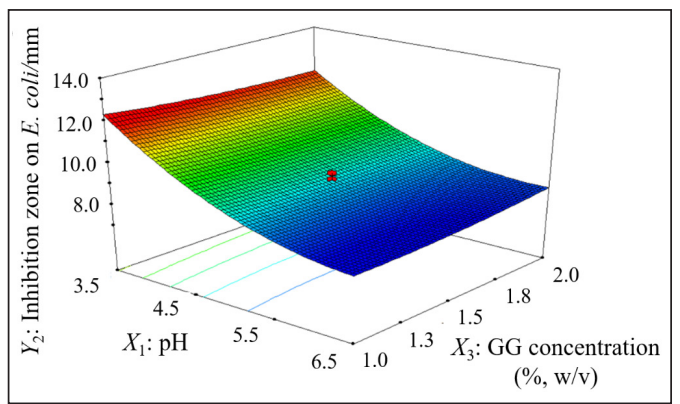

(b)

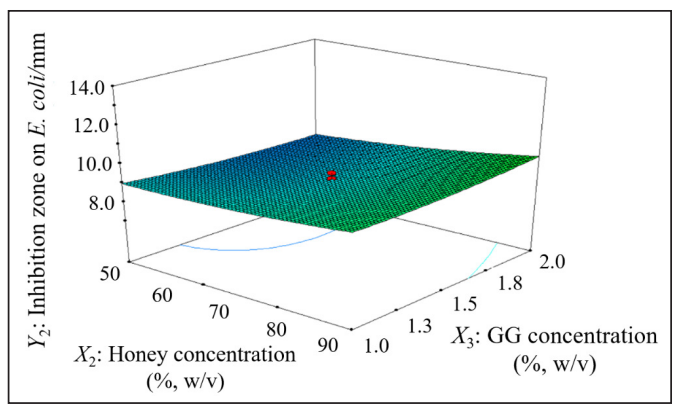

(c)

Figure 1. Response surface plot showing the effect Figure 2. Response surface plot showing the effect of $\mathrm{pH}\left(X_{1}\right)$, honey concentration $\left(X_{2}\right)$, and guar gum of $\mathrm{pH}\left(X_{1}\right)$, honey concentration $\left(X_{2}\right)$, and guar gum concentration $\left(X_{3}\right)$ on inhibition zones against $S$. aureus concentration $\left(X_{3}\right)$ on inhibition zones against $E$. coli $\operatorname{ATCC} 6538\left(Y_{1}\right)$. (a) $X_{1} X_{2}$, (b) $X_{1} X_{3}$, and (c) $X_{2} X_{3}$ $\operatorname{ATCC} 8739\left(Y_{1}\right)$. (a) $X_{1} X_{2}$, (b) $X_{1} X_{3}$, and (c) $X_{2} X_{3}$ 


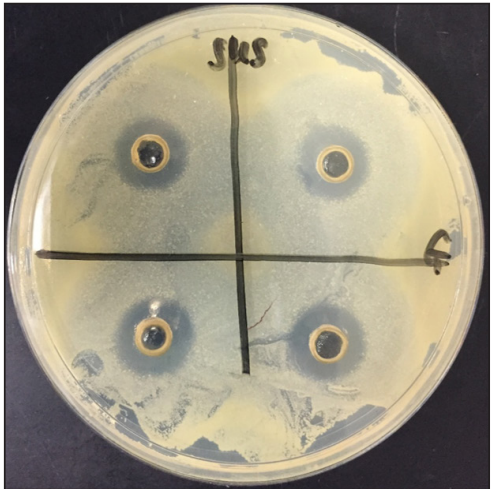

(a)

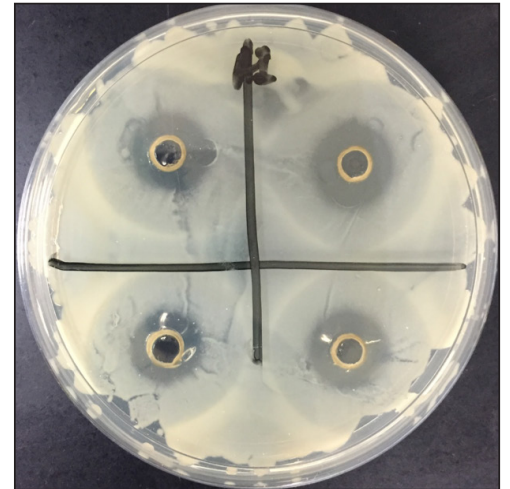

(b)

Figure 3. Formation of inhibition zone on: (a) S. aureus ATCC 6538; and (b) E. coli ATCC 8739 (right) in response to optimal preparation prepared using guar gum as polymeric agent

gum concentration. This indicates that the $\mathrm{pH}$ and guar gum concentration did not show any interaction affecting the zone of inhibition. The analysis of Figure 1 (b) and Figure 2 (b) revealed that there was no optimal concentration of guar gum in the inhibition zones of $S$. aureus and E. coli. The insignificant effect could be due to the use of a narrow range of guar gum concentration between $1 \%$ and $2 \%$. Although the range has been reported to significantly affect the rheological properties of the preparation (Mulye et al., 2014), it does not significantly affect the zone of inhibition.

Figure 1 (c) and Figure 2 (c) present 3D plots and their corresponding contour plots showing the effect of honey concentration $\left(X_{2}\right)$ and guar gum concentration $\left(X_{3}\right)$ on the inhibition zones of $S$. aureus and E. coli, while the pH was fixed at its middle level, i.e., 5.0. Based on the results obtained, honey concentration is directly proportional to the inhibition zones of both $S$. aureus and $E$. coli regardless on the variation of guar gum concentrations between $1.0 \%$ and $2.0 \%(\mathrm{w} / \mathrm{v})$. As for the guar gum concentration, the inhibition zones were consistent at any tested concentrations between $1.0 \%$ and $2.0 \%(\mathrm{w} / \mathrm{v})$ regardless of the concentration of honey used. Thus, it can be concluded that there is a lack of interaction between the concentration of honey and guar gum in response to the inhibition zone.

According to the analysis, the inhibition zones of $12.7 \mathrm{~mm}$ for $S$. aureus and 13.1 $\mathrm{mm}$ for $E$. coli were predicted for the optimal preparation with $\mathrm{pH}$ of 3.5, the honey concentration of $90 \%(\mathrm{w} / \mathrm{v})$, and guar gum concentration of $1.5 \%(\mathrm{w} / \mathrm{v})$. The experiments were performed to verify the results, and the observed responses are tabulated in Table 6. Based on the conducted experiment, the inhibition zones obtained are $12.5 \mathrm{~mm}$ for $S$. aureus and $13.5 \mathrm{~mm}$ for $E$. coli, respectively (Figure 3). The results were congruent to the model's prediction, with the percentage of difference of $1.6 \%$ for $S$. aureus and $3.1 \%$ for $E$. coli, respectively. The findings confirmed the reliability of the models developed to predict the responses with less than 10\% variation (Madiha et al., 2017; Shahzad et al., 2012). 
Table 6

Summary of the predicted and observed responses for the optimal preparation

\begin{tabular}{lcccc}
\hline \multicolumn{1}{c}{ Factor } & \multicolumn{3}{c}{ Optimal value } \\
\hline $\mathrm{pH}$ & & 3.5 & \\
Honey concentration $(\%, \mathrm{w} / \mathrm{v})$ & & 90 & \\
Guar gum concentration $(\%, \mathrm{w} / \mathrm{v})$ & & & 1.5 & \\
\hline \multicolumn{1}{c}{ Response } & Predicted & Observed & Residual & Prediction error $(\%)$ \\
\hline Inhibition zone on $S$. aureus $(\mathrm{mm})$ & 12.7 & 12.5 & \pm 0.2 & 1.6 \\
Inhibition zone on $E$. coli $(\mathrm{mm})$ & 13.1 & 13.5 & \pm 0.4 & 3.1 \\
\hline
\end{tabular}

\section{Evaluations of the Optimal Preparation}

The physicochemical properties of the optimal preparations were evaluated in terms of physical appearance, homogeneity, colour, grittiness, lump formation, $\mathrm{pH}$, viscosity, and centrifugation test. The results are tabulated in Table 7.

Table 7

Physicochemical properties of the optimal preparation

\begin{tabular}{lc}
\hline Formulation & Guar gum \\
\hline Physical appearance & Opaque \\
Homogeneity & Homogeneous \\
Colour & Dark brown \\
Grittiness & No \\
Lump formation & No \\
pH & $3.53 \pm 0.70$ \\
Viscosity at 100rpm (cps) & $2470 \pm 120.1$ \\
Centrifugation Test & No phase separation observed \\
\hline
\end{tabular}

The symbol \pm represents the standard deviation which was calculated between three biological replicates.

The preparation resulted in opaque, homogeneous, and dark brown colour, as shown in Figure 4. No grittiness and formation of the lump were observed in the preparation. The $\mathrm{pH}$ of the preparation was recorded at $3.53 \pm 0.70$. The $\mathrm{pH}$ recorded can be considered suitable for topical preparation, as the $\mathrm{pH}$ ranging between 2.8 and 7.4 was acceptable for therapeutic effect with non-irritant effect on human skin (Dantas et al., 2016; Panther \& Jacob, 2015).

The viscosity of the preparation was measured at $2470 \pm 120.1 \mathrm{cps}$. The viscosity was within the range that was sufficient for good spreadability and clarity. The viscosity appropriate for topical preparation was recorded between 512 and $15000 \mathrm{cps}$ (Chen et al., 2016; Pande et al., 2014; Singh et al., 2013). 


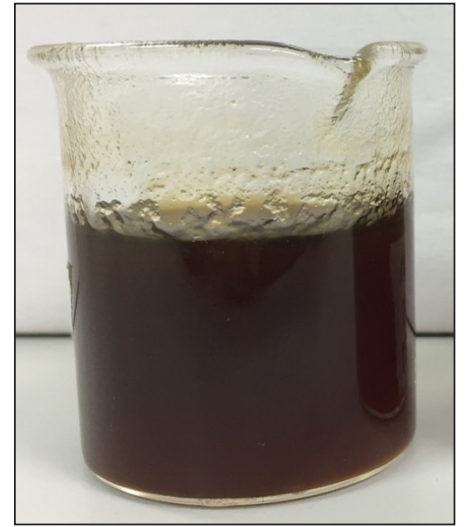

Figure 4. Physical appearance of the optimal preparations prepared using guar gum

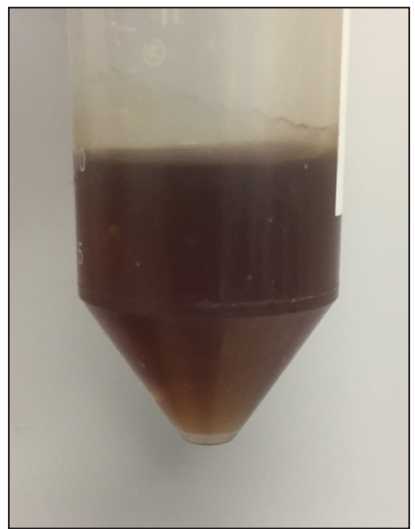

(a)

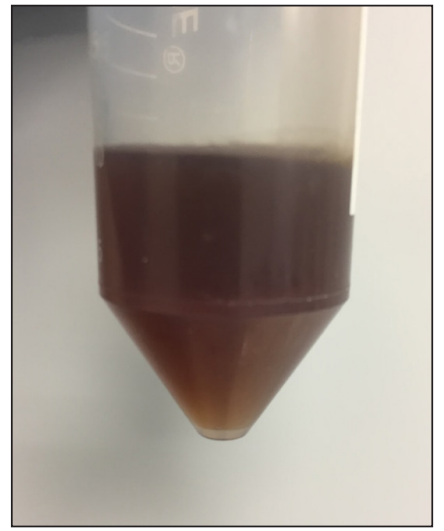

(b)

Figure 5. Appearance of the preparations: (a) before; and (b) after centrifugation test

The centrifugation test was also conducted to evaluate the gravitational effect on the preparation. This is essential to analyse the adequate quality and stability of the preparation (Dimeski et al., 2011; Iradhati \& Jufri, 2017). Based on the results obtained, no noticeable instability was observed on the optimal preparation upon spinning at $151 \mathrm{~g}$ for $30 \mathrm{~min}$ at $25^{\circ} \mathrm{C}$. The preparation remained intact without phase separation, indicating adequate and stable formulation (Figure 5).

\section{Antibacterial Efficacy}

The antibacterial efficacy of the optimal preparation was evaluated through the measurement of the inhibition zone and formation of a bacterial colony to indicate the presence of bacteriostatic and bactericidal of the preparation.

Measurement of Inhibition Zone. The results for the inhibition zone measurements are shown in Figure 6 (a) for Gram-positive, and Figure 6 (b) for Gram-negative bacteria. The range of inhibition zone measured for the optimal preparation was between $8.8 \pm 0.76 \mathrm{~mm}$ and $14.7 \pm 0.58 \mathrm{~mm}$, indicating that the bacteria reacted as sensitive towards the preparation. The lowest inhibition zone was measured on P. aeruginosa ATCC 27853, while the largest inhibition zone was measured on $S$. haemolyticus.

In the commercially available preparation using manuka, the inhibition zone was measured in the range between $8.7 \pm 0.58 \mathrm{~mm}$ and $16.7 \pm 0.58 \mathrm{~mm}$, with the smallest inhibition zone measured on K. pneumonia, while the largest on S. agalactiae, respectively. Based on the range of inhibition zones measured, the tested bacteria reacted between sensitive to very sensitive towards the manuka preparation. 
In comparison with the guar gum preparation, none of the inhibition zones measured was larger than the manuka preparation for Gram-positive bacteria. Whereas for Gramnegative bacteria, out of 14 species, the preparation using guar gum showed the inhibition zone of $9.0 \pm 0.00 \mathrm{~mm}$ and $12.7 \pm 0.58 \mathrm{~mm}$ on $K$. pneumonia ATCC BAA 1144 and $E$. cloacae, which were 1.03 and 1.09-fold larger compared to manuka, with the inhibition zones of $8.7 \pm 0.58 \mathrm{~mm}$ and $11.7 \pm 0.58 \mathrm{~mm}$, respectively. The remaining 12 species of Gram-negative bacteria were inhibited with larger inhibition zones by manuka preparation.

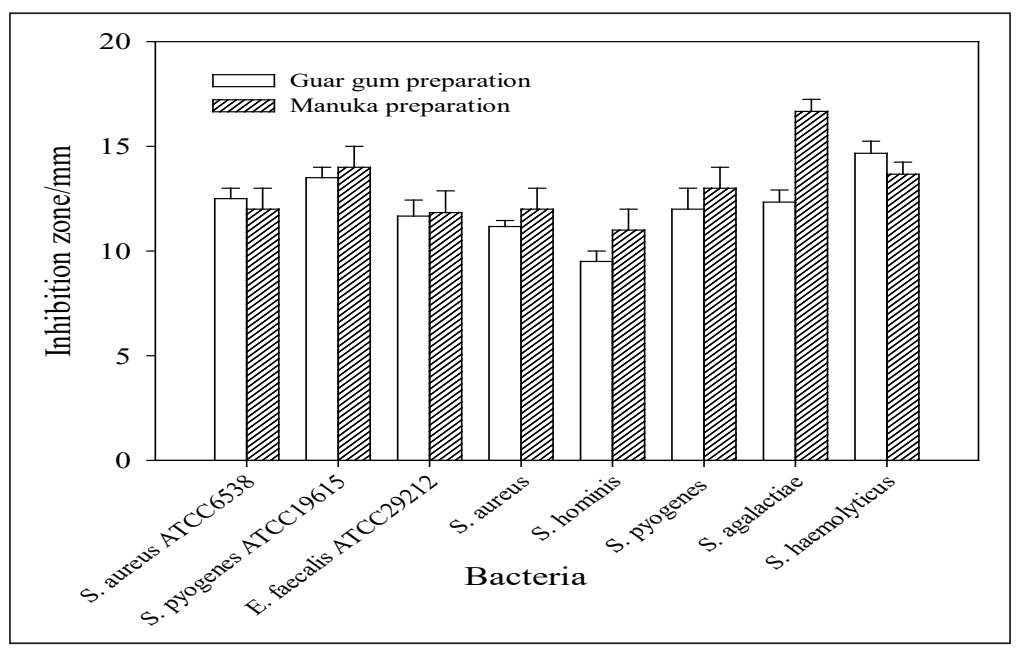

(a)

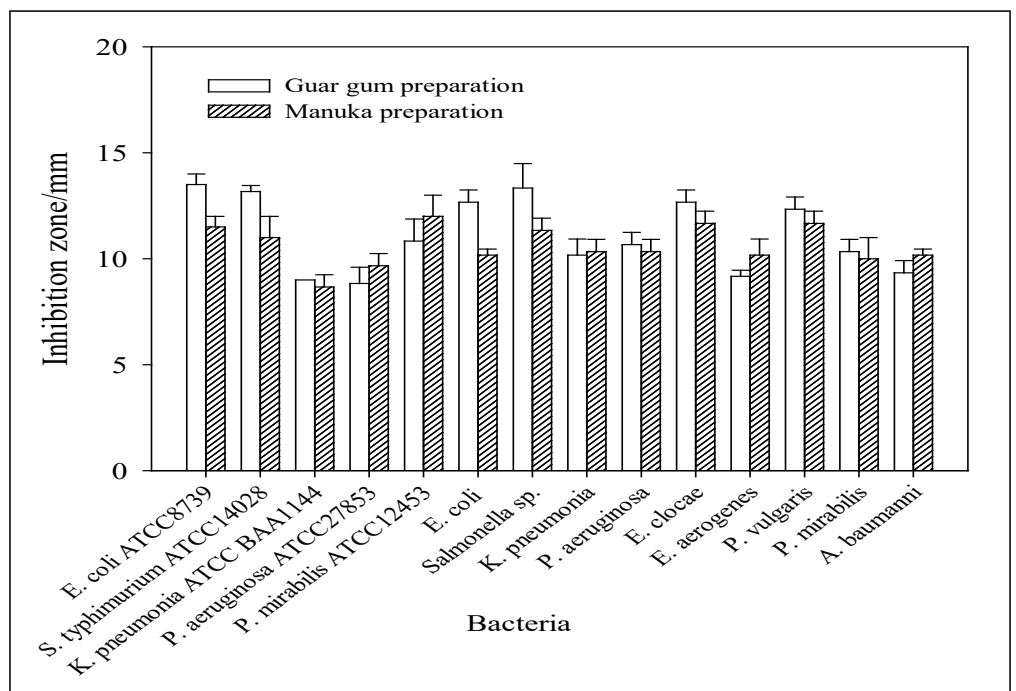

(b)

Figure 6 . The inhibition zone measured by the preparations tested against the standard laboratory and clinical isolated bacteria of: (a) Gram-positive; and (b) Gram-negative. Error bars symbolise the errors calculated from three biological replicates. One sample t-test represent significant differences between the mean of the sampled population and the hypothesised population mean $(P$-value $<0.05)$ 
Bactericidal Effect. An attempt was made to investigate the ability of the preparation to kill bacteria through the formation of a bacterial colony. The results are tabulated in Table 8 for Gram-positive, and Table 9 for Gram-negative, respectively.

In the 22 tested bacteria, no formation of the bacterial colony was observed on the surface of agar for guar gum preparation after $24 \mathrm{~h}$ of incubation, indicating the presence of bactericidal effect (Dewanjee et al., 2008; Shagana \& Geetha, 2017). Figure 7 and Figure 8 show the absence of bacterial colony on the surface of agar tested on Gram-positive $(S$.

Table 8

The results on formation of bacterial colony for Gram-positive

\begin{tabular}{|c|c|c|c|}
\hline & \multicolumn{3}{|c|}{ Formation of bacterial colony } \\
\hline & Guar gum & Manuka & Control (broth only) \\
\hline \multicolumn{4}{|c|}{ Standard strain } \\
\hline S. aureus ATCC6538 & No & No & Yes \\
\hline S. pyogenes ATCC19615 & No & No & Yes \\
\hline E. faecalis ATCC29212 & No & Yes & Yes \\
\hline \multicolumn{4}{|c|}{ Clinical isolated strain } \\
\hline S. aureus & No & No & Yes \\
\hline S. hominis & No & No & Yes \\
\hline S. pyogenes & No & No & Yes \\
\hline S. agalactiae & No & No & Yes \\
\hline S. haemolyticus & No & No & Yes \\
\hline
\end{tabular}

Table 9

The results on formation of bacterial colony for Gram-negative bacteria

\begin{tabular}{lccc}
\hline & \multicolumn{2}{c}{ Formation of bacterial colony } \\
\cline { 2 - 4 } & Guar gum & Manuka & Control (broth only) \\
\hline E. coli ATCC 8739 & Standard strain & & Yes \\
S. typhimurium ATCC14028 & No & No & Yes \\
K. pneumonia ATCCBAA1144 & No & No & Yes \\
P. aeruginosa ATCC27853 & No & No & Yes \\
P. mirabilis ATCC12453 & No & No & Yes \\
\hline & No & & Yes \\
\hline E. coli & Clinical isolated strain & No & Yes \\
Salmonella sp. & No & No & Yes \\
K. pneumonia & No & No & Yes \\
$P$. aeruginosa & No & No & Yes \\
E. clocae & No & No & Yes \\
E. aerogenes vulgaris & No & No & Yes \\
P. mirabilis & No & No & Yes \\
A. baumannii & No & No & Yes \\
\hline
\end{tabular}


aureus, E. faecalis ATCC 29212, S. hominis, and S. haemolyticus) and Gram-negative (E. coli, P. aeruginosa, Salmonella sp., and K. pneumonia) bacteria, respectively. Similar results were demonstrated by the preparation of manuka, except on E. faecalis ATCC
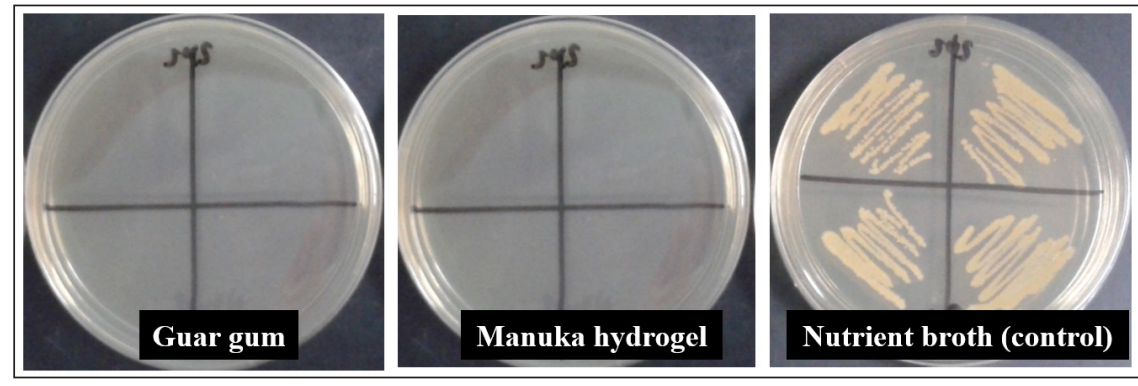

(a)
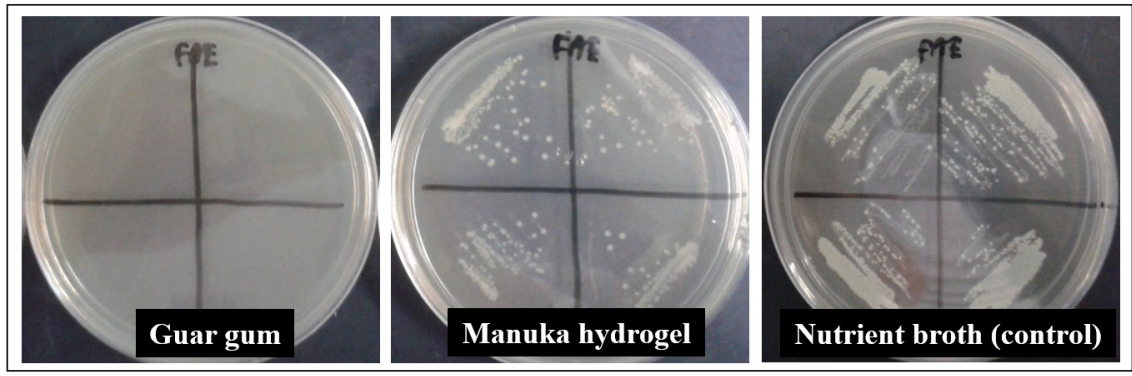

(b)
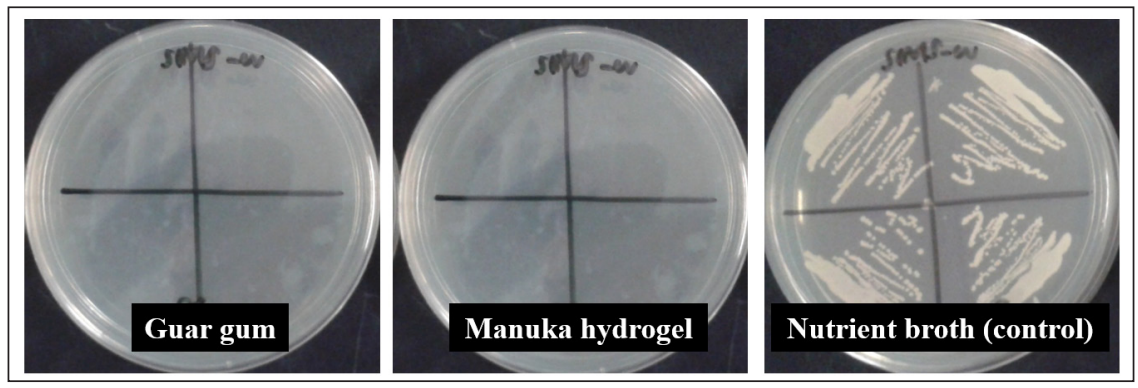

(c)
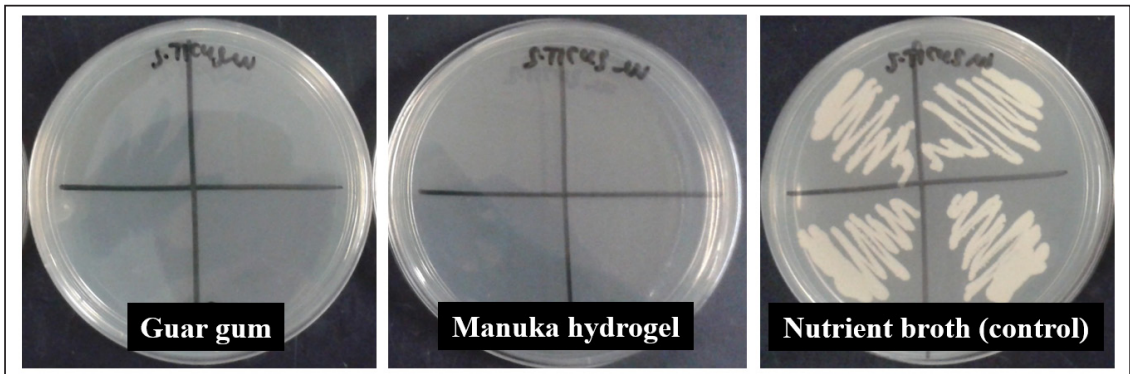

(d)

Figure 7. The results on formation of bacterial colony on the surface of agar for Gram-positive bacteria: (a) S. aureus; (b) E. faecalis ATCC 29212; (c) S. hominis; and (d) S. haemolyticus. 
29212, where the formation of bacterial colonies was observed. The ability of E. faecalis to survive could be due to the development of a resistant mechanism, such as biofilm formation to combat the effectiveness of antibacterial agent (Gopinath \& Prakash, 2013).

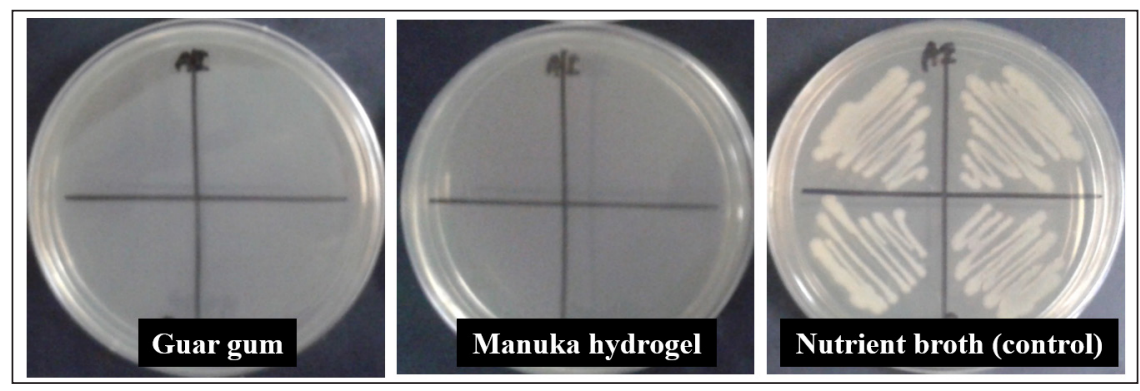

(a)

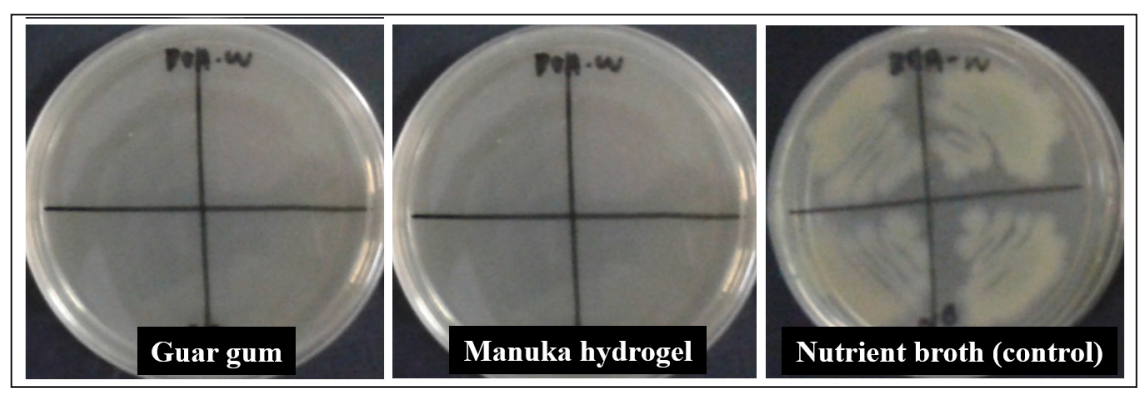

(b)

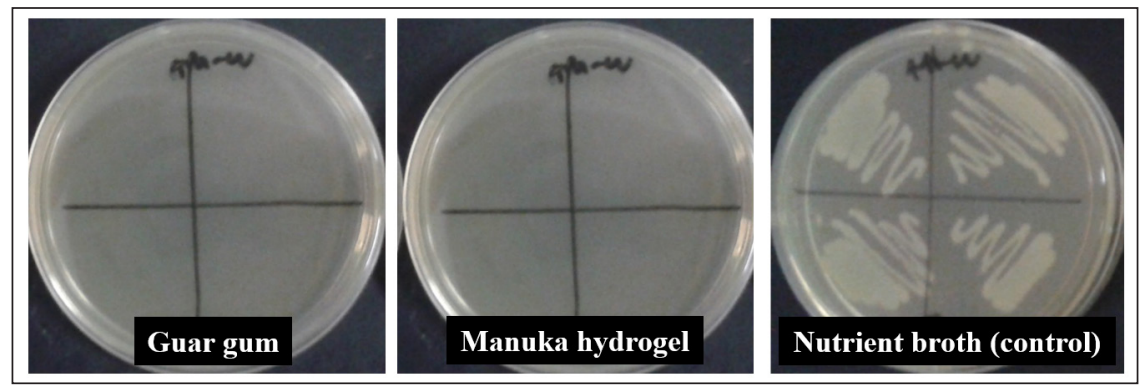

(c)

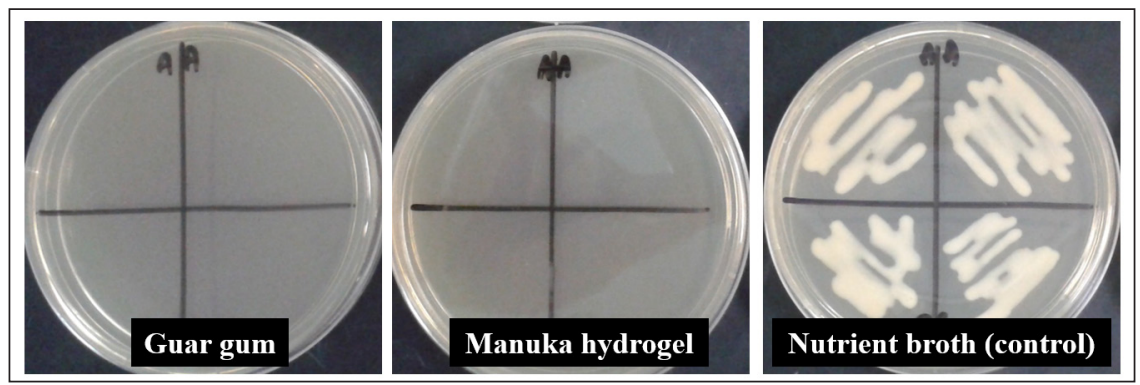

(d)

Figure 8 . The results on formation of bacterial colony on the surface of agar for Gram-negative bacteria: (a) E. coli; (b) P. aeruginosa; (c) Salmonella sp.; and (d) K. pneumonia 
The outcome was similar to those obtained from a previous study (Mohd-Aspar \& Edros, 2019), which reported the highest concentration of manuka honey at $25 \%(\mathrm{w} / \mathrm{v})$ required to kill E. faecalis compared to other bacterial species. In the control sample, where the bacteria were cultured in broth alone, the formation of bacteria colonies was observed for all 22 bacteria, indicating the absence of a bactericidal effect.

In many types of acute and chronic wounds, $S$. aureus and $P$. aeruginosa are usually isolated from infected wounds (Negut et al., 2018; Serra et al., 2015). These bacteria often cause biofilm development and chronic infections that may suppress immune activities and promote the development of antibiotic-resistant strains (Serra et al., 2015). Similar to S. aureus and P. aeruginosa, other wound-associated bacteria such as E. coli, S. pyogenes, $E$. faecalis, and $P$. mirabilis can also develop biofilms, antimicrobial inactivating enzymes, and other resistance mechanisms to eliminate the antibacterial action (Kim et al., 2018; Lu et al., 2014). In this study, 22 wound-associated bacteria, which include standard laboratory and clinical strains isolated from infected wounds, have been tested and were found to be susceptible to the preparation. This was proven by the formation of inhibition zone and the presence of bactericidal effect for both preparations against the tested bacteria. The results indicate that guar gum was effective in conveying the kelulut honey as a topical preparation without compromising its antibacterial properties.

Stability Study. The stability study was conducted by keeping the preparation at an extended period $\left(25^{\circ} \mathrm{C} \pm 2 / 60 \% \pm 5 \mathrm{RH}\right)$ and accelerated storage $\left(40^{\circ} \mathrm{C} \pm 2 / 75 \% \pm 5 \mathrm{RH}\right)$ conditions for six months. The physicochemical properties, i.e., colour, homogeneity, $\mathrm{pH}$, and viscosity, and antibacterial efficacy (inhibition zone and formation of the bacterial colony) of the preparation was determined at $0,1,2,3$, and 6 months.

Physicochemical Properties. The results for the physicochemical properties of the preparation are shown in Table 10 for colour, homogeneity, and $\mathrm{pH}$, and Figure 9 for viscosity, respectively. According to the results obtained, the colour, homogeneity, and $\mathrm{pH}$ of the preparation after six months of storage remained unchanged. The $\mathrm{pH}$ of the guar gum preparation was measured to be in the range between $3.41 \pm 0.10$ and $3.53 \pm 0.10$. The difference between the lowest and highest $\mathrm{pH}$ levels was $4 \%$. The ability to maintain the fundamental physicochemical properties indicates adequate and reliable preparation (Chen et al., 2016).

The viscosity of the guar gum preparation was inversely proportional with time. The highest viscosity of $2470 \pm 174.4 \mathrm{cps}$ for the long-term and $2533 \pm 285.0 \mathrm{cps}$ for the accelerated storage were measured at 0 months, respectively. After six months of storage, the lowest viscosity of $1247 \pm 130.5 \mathrm{cps}$ for the long-term and $800 \pm 200.0 \mathrm{cps}$ for the accelerated storage were recorded, respectively. The variation in viscosity between 
Table 10

The results for colour, homogeneity, and $\mathrm{pH}$ during six months stability test of the preparation

\begin{tabular}{|c|c|c|c|c|c|c|c|c|c|c|}
\hline & \multicolumn{5}{|c|}{ Long term $-25^{\circ} \mathrm{C} \pm 2 / 60 \% \mathrm{RH} \pm 5$} & \multicolumn{5}{|c|}{ Accelerated $-40^{\circ} \mathrm{C} \pm 2 / 75 \% \mathrm{RH} \pm 5$} \\
\hline & \multicolumn{5}{|c|}{ Months } & \multicolumn{5}{|c|}{ Months } \\
\hline & 0 & 1 & 2 & 3 & 6 & 0 & 1 & 2 & 3 & 6 \\
\hline Color & \multicolumn{5}{|c|}{ Dark brown } & \multicolumn{5}{|c|}{ Dark brown } \\
\hline Homogeneity & \multicolumn{5}{|c|}{ Homogeneous } & \multicolumn{5}{|c|}{ Homogeneous } \\
\hline $\mathrm{pH}$ & $\begin{array}{c}3.53 \\
\pm 0.06 \\
\end{array}$ & $\begin{array}{c}3.51 \\
\pm 0.06\end{array}$ & $\begin{array}{c}3.52 \\
\pm 0.07\end{array}$ & $\begin{array}{c}3.47 \\
\pm 0.06\end{array}$ & $\begin{array}{c}3.43 \\
\pm 0.04\end{array}$ & $\begin{array}{c}3.47 \\
\pm 0.17\end{array}$ & $\begin{array}{c}3.45 \\
\pm 0.10\end{array}$ & $\begin{array}{c}3.43 \\
\pm 0.08 \\
\end{array}$ & $\begin{array}{c}3.45 \\
\pm 0.09\end{array}$ & $\begin{array}{c}3.41 \\
\pm 0.10 \\
\end{array}$ \\
\hline
\end{tabular}

The symbol \pm represents the standard deviation which calculated between three biological replicates. Student's $\mathrm{t}$-test shown significant differences for the $\mathrm{pH}$-value measured.

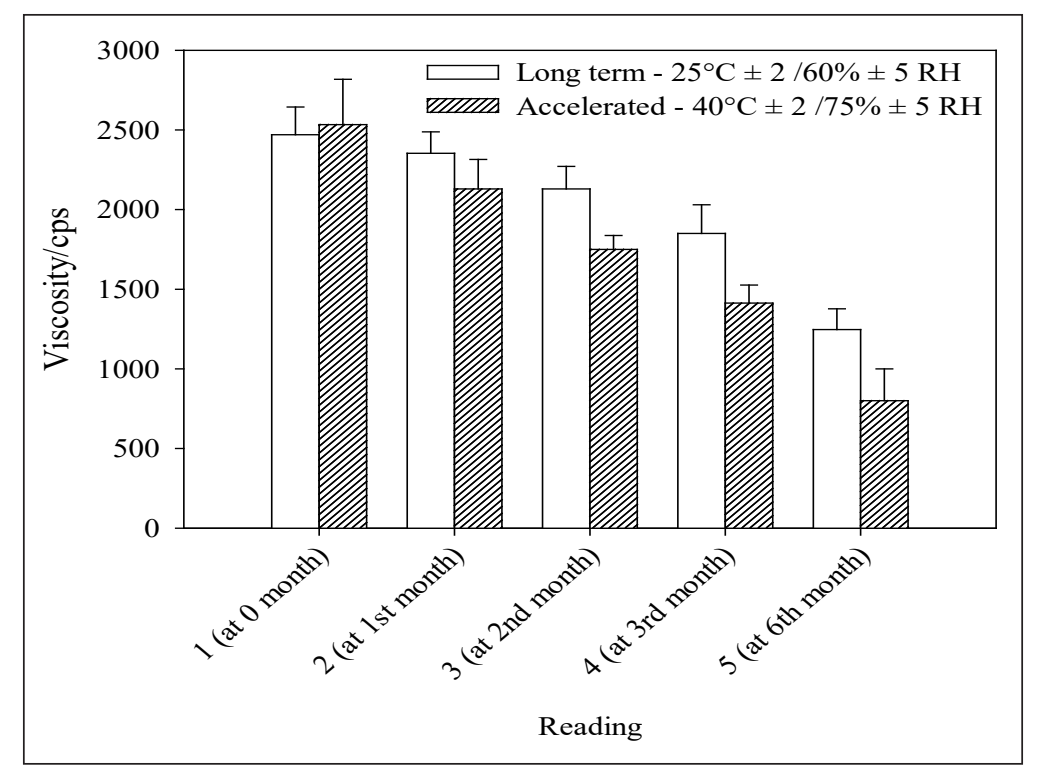

Figure 9. Viscosity of the preparation during the six-month of stability study after been stored at long term $\left(25^{\circ} \mathrm{C} \pm 2 / 60 \% \pm 5 \mathrm{RH}\right)$ and accelerated $\left(40^{\circ} \mathrm{C} \pm 2 / 75 \% \pm 5 \mathrm{RH}\right)$ storing conditions. Error bars symbolise the errors calculated from three biological replicates. Student's t-test shown significant differences for the data collected

measurements at 0 month and sixth month was $50 \%$ for the long-term and $68 \%$ for the accelerated storage.

A continuous reduction in viscosity within the six months of stability study, as demonstrated by the guar gum preparation, indicate an unstable preparation. This could be due to incomplete dispersal or solubility of guar gum to form a stable structure that resulted from the limited amount of water (Hemendrasinh \& Dhruti, 2015) due to the reaction of guar gum molecules that compete with sugar for water availability (Mudgil et al., 2014). The temperature is another factor that affects the stability of the guar gum solution. The prolonged heat of guar gum solution may result in thermal degradation that leads to unstable 
solubilisation of the guar gum (Mudgil et al., 2014; Yagoub \& Nur, 2013). In this study, as the guar gum preparation was stored in extreme storage, the viscosity of the preparation was reduced, indicating an unstable preparation. The outcome is in congruent with the previous study that reported an unstable viscosity of guar gum preparation at high temperature (Yagoub \& Nur, 2013). Storage at the ambient temperature $\left(25^{\circ} \mathrm{C}\right)$ is considered sufficient for maintaining the viscosity of the guar gum preparation over long-term.

Antibacterial Efficacy. The antibacterial efficacy of the preparation within the six months of stability study was evaluated through the measurement of inhibition zone and formation of a bacterial colony. The measurement of the inhibition zone on Gram-positive and Gramnegative bacteria are shown in Figure 10 (a) and Figure 10 (b), respectively. Meanwhile, the results for the formation of the bacterial colony are tabulated in Table 11.

The inhibition zone measured for guar gum preparation ranged from $9.0 \pm 0.00 \mathrm{~mm}$ to $12.8 \pm 1.30 \mathrm{~mm}$. The zone of inhibition showed an average variation of $7.8 \%$ between the initial and final measurements within the six-month stability study. As for the formation of a bacterial colony, the preparation remained valid to prevent the formation of the bacterial colony within the six months of the stability study. Based on the outcomes obtained from both evaluations, the efficacy of the preparation remained effective without a deficiency, indicating a stable and reliable preparation capable of maintaining its antibacterial properties over time (Irish et al., 2011).

The synergistic interaction is considered positive if the therapeutic effect initially present in the preparation remains uninterrupted. The results indicated that the preparation prepared in this study is capable of retaining the antibacterial properties, as proven by the identical inhibition zone and bactericidal effect. The uninterrupted antibacterial properties could be explained by the stable polymeric agent to maintain the crosslinking network and uniformed dispersion of honey across the preparation (Sharma et al., 2015; Zhu et al., 2019). In addition, the interactions between the charges of the polymeric agent, i.e.,

Bactericidal effect for the six-month of stability study for the optimal preparation

\begin{tabular}{lccccccccccc}
\hline & \multicolumn{3}{c}{ Long-term } & \multicolumn{5}{c}{ Accelerated } \\
& \multicolumn{4}{c}{$25^{\circ} \mathrm{C} \pm 2 / 60 \% \pm 5 \mathrm{RH}$} & \multicolumn{5}{c}{$40^{\circ} \mathrm{C} \pm 2 / 75 \% \pm 5 \mathrm{RH}$} \\
\cline { 2 - 11 } & 0 & 1 & 2 & 3 & 6 & 0 & 1 & 2 & 3 & 6 \\
\hline S. aureus & Yes & Yes & Yes & Yes & Yes & Yes & Yes & Yes & Yes & Yes \\
E. faecalis ATCC 29212 & Yes & Yes & Yes & Yes & Yes & Yes & Yes & Yes & Yes & Yes \\
S. pyogenes & Yes & Yes & Yes & Yes & Yes & Yes & Yes & Yes & Yes & Yes \\
E. coli & Yes & Yes & Yes & Yes & Yes & Yes & Yes & Yes & Yes & Yes \\
K. pneumoniae & Yes & Yes & Yes & Yes & Yes & Yes & Yes & Yes & Yes & Yes \\
E. aerogenes & Yes & Yes & Yes & Yes & Yes & Yes & Yes & Yes & Yes & Yes \\
\hline
\end{tabular}




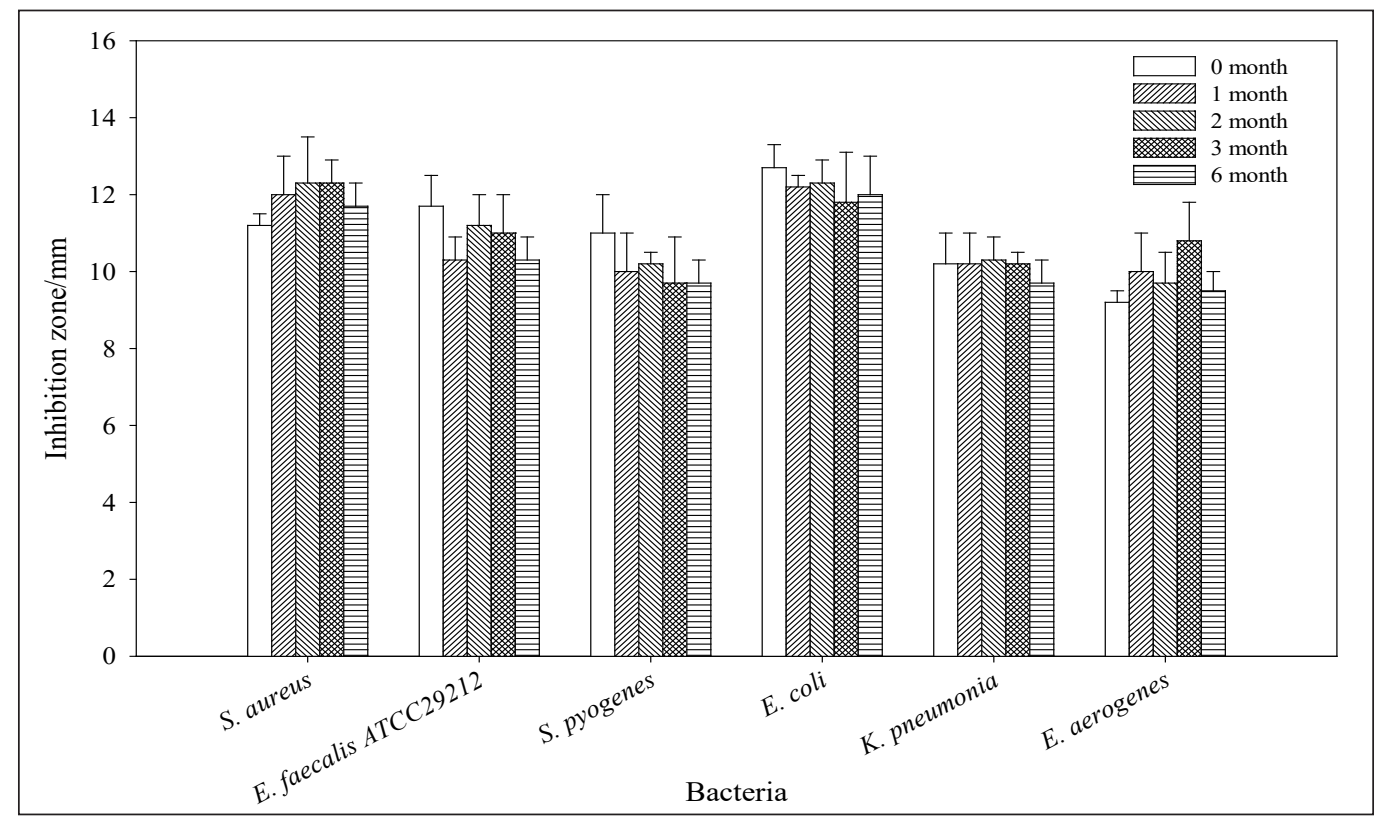

(a)

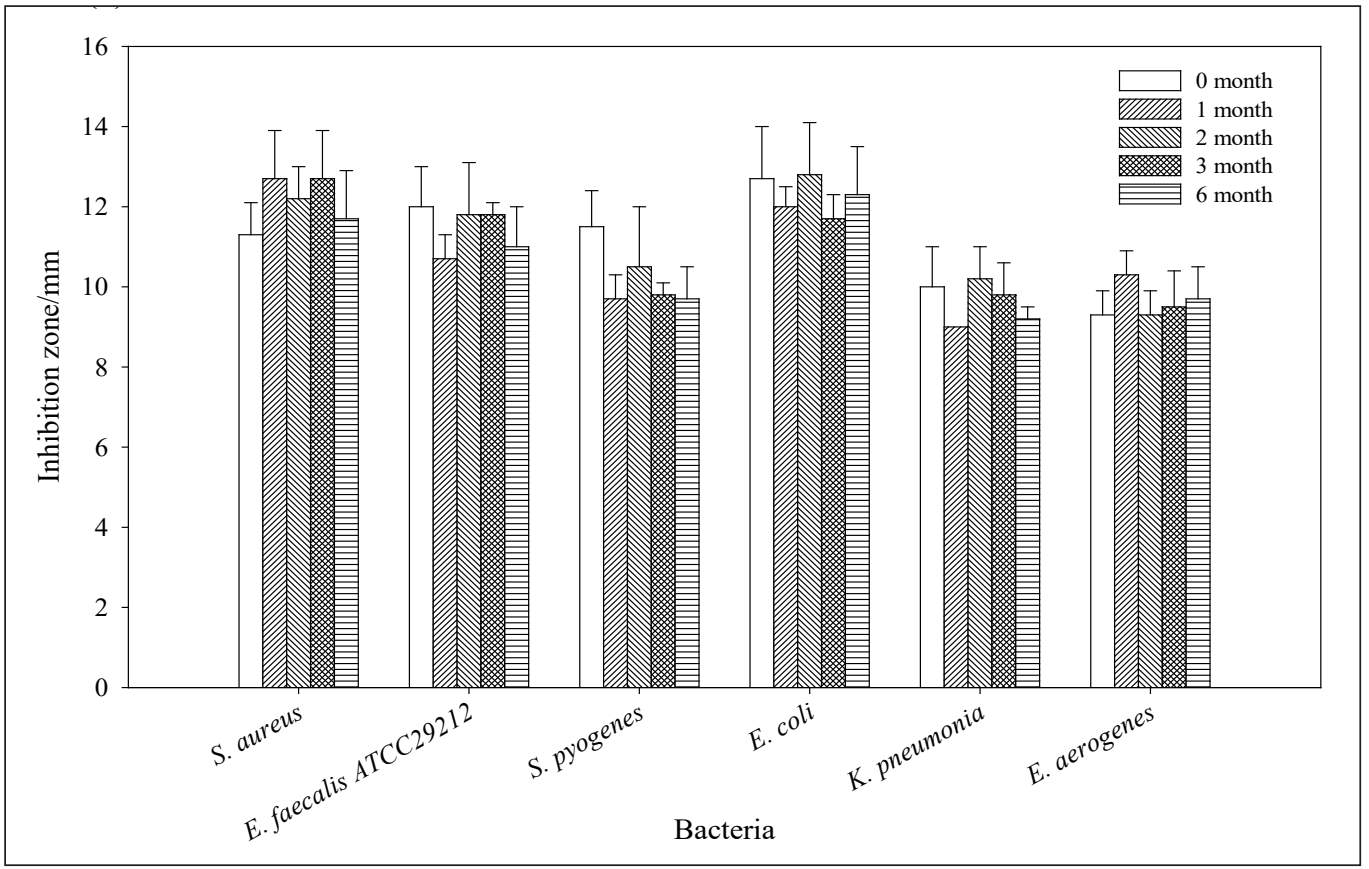

(b)

Figure 10. Measurement of inhibition zone for the optimal preparation using guar gum after stored in: (a) long-term and $-25^{\circ} \mathrm{C} \pm 2 / 60 \% \pm 5 \mathrm{RH}$; and (b) accelerated $-40^{\circ} \mathrm{C} \pm 2 / 75 \% \pm 5 \mathrm{RH}$ storage conditions. Error bars symbolise the errors calculated from three biological replicates. One sample t-test represent significant differences between the mean of the sampled population and the hypothesised population mean $(P$-value $<0.05)$ 
guar gum loaded with honey and the charges on the surface of the bacterial membrane formed a contact (Kaith et al., 2015) that allow the compounds such as phenolic acids and flavonoids to promote cell disruption and lysis to kill the bacteria (Henriques et al., 2010; Henriques et al., 2011). A similar finding with the positive synergistic effect of honey in preparation that led to more than $95 \%$ of drug release was demonstrated by the previous study (El-Kased et al., 2017).

\section{CONCLUSION}

The use of guar gum as a polymeric agent was appropriate for the preparation of kelulut honey as a topical preparation. The optimal preparation was finalised at $\mathrm{pH} 3.5$, honey concentration of $90 \%(\mathrm{w} / \mathrm{v})$, and guar gum concentration of $1.5 \%(\mathrm{w} / \mathrm{v})$. The optimal preparation demonstrated reliable physicochemical properties, and most importantly, the potent antibacterial properties, including both bacteriostatic and bactericidal effects were retained on the 22 bacteria species after the honey was converted to a topical preparation. However, within the six months of stability study, the viscosity of the preparation was reduced to more than $50 \%$ between the initial ( 0 month) and final ( 6 months) measurements. Consideration of the addition of stabilising or preservative agent is recommended to overcome the reduction of viscosity over time.

\section{ACKNOWLEDGEMENT}

The authors would like to thank the Ministry of Education Malaysia in providing the fund for this project under the Fundamental Research Grant Scheme (FRGS; Grant Number: FRGS/1/2017/STG05/UMP/02/5) and Postgraduate Research Grant Scheme (PGRS190358), Universiti Malaysia Pahang (UMP) for the research facilities and IIUMC for providing the clinical bacterial strains.

\section{REFERENCES}

Ammer, R. M., Zaman, S., Khalid, M., Bilal, M., Erum, S., Huang, D., \& Che, S. (2016). Optimization of antibacterial activity of Eucalyptus tereticornis leaf extracts against Escherichia coli through response surface methodology. Journal of Radiation Research and Applied Sciences, 9(4), 376-385. doi: https:// doi.org/10.1016/j.jrras.2016.05.001

Anitha, G., \& Pandey, V. P. (2016). Review on: Statistical designs and response surface methodology (RSM) as a tool for the optimization of HPLC methods. International Journal of Pharmacy and Analytical Research, 5(4), 552-569.

Bakar, M. F. A., Sanusi, S. B., Bakar, F. I. A., Cong, O. J., \& Mian, Z. (2017). Physicochemical and antioxidant potential of raw unprocessed honey from Malaysian stingless bees. Pakistan Journal of Nutrition, 16(11), 888-894. doi: https://doi.org/10.3923/pjn.2017.888.894 
Boukraâ, L. (Ed.). (2014). Honey in traditional and modern medicine. New York, USA: Taylor \& Francis Group. doi: https://doi.org/10.1201/b15608

Brudzynski, K., \& Sjaarda, C. (2014). Antibacterial compounds of Canadian honeys target bacterial cell wall inducing phenotype changes, growth inhibition and cell lysis that resemble action of ß-Lactam antibiotics. PLoS One, 9(9), 1-11. doi: https://doi.org/10.1371/journal.pone.0106967.g003

Chen, M. X., Alexander, K. S., \& Baki, G. (2016). Formulation and evaluation of antibacterial creams and gels containing metal ions for topical application. Journal of Pharmaceutics, 2016, 1-10. doi: https:// doi.org/10.1155/2016/5754349

Dantas, M. G. B., Reis, S. A. G., Damasceno, C. M. D., Rolim, L. A., Rolim-neto, P. J., Carvalho, F. O., ... \& Almeida, J. R. G. da S. (2016). Development and evaluation of stability of a gel formulation containing the monoterpene borneol. The Scientific World Journal, 2016, 1-5. doi: https://doi.org/10.1155/2016/7394685

Dewanjee, S., Maiti, A., Majumdar, R., Majumdar, A., \& Mandal, S. C. (2008). Evaluation of antimicrobial activity of hydroalcoholic extract Schima wallichii bark. Pharmacologyonline, 1, 523-528.

Dimeski, G., Solano, C., Petroff, M. K., \& Hynd, M. (2011). Centrifugation protocols: Tests to determine optimal lithium heparin and citrate plasma sample quality. Annals of Clinical Biochemistry, 48(3), 218222. doi: https://doi.org/10.1258/acb.2010.010230

Dluya, T. (2016). Critical review: Antioxidant properties and antibiotic mechanism of honey against infectious diseases. International Journal of Advances in Life Science and Technology, 2, 16-24. doi: https://doi. org/10.18488/journal.72/2015.2.2/72.2.16.24

El-Kased, R. F., Amer, R. I., Attia, D., \& Elmazar, M. M. (2017). Honey-based hydrogel: In vitro and comparative in vivo evaluation for burn wound healing. Scientific Reports, 7(1), 1-11. doi: https://doi. org/10.1038/s41598-017-08771-8

Franklin, R. C., Matthew, A. W., Jeff, A., Michael, N. D., George, M. E., Mary, J. F., ... \& Barbara, L. Z. (2012). Methods for dilution antimicrobial susceptibility tests for bacteria that grow aerobically: Approved standard - Ninth Edition (Vol. 32). Wayne, USA. Retrieved July 20, 2020, from https://mafiadoc.com/ download/methods-for-dilution-antimicrobial-susceptibility-tests-_5a19a8801723dd4f2ac359bc.html

Gopinath, R., \& Prakash, M. (2013). Antibacterial activity of three medicinal plants against clinically isolated multidrug resistant Enterococcus faecalis (MDRE). International Journal of Current Microbiology and Applied Sciences, 2(2), 6-14.

Hemendrasinh, J. R., \& Dhruti, P. M. (2015). A review on pharmaceutical gel. International Journal of Pharmaceutical Sciences, 1(1), 33-47.

Henriques, A. F., Jenkins, R. E., \& Burton, N. F. (2010). The intracellular effects of manuka honey on Staphylococcus aureus. European Journal of Clinical Microbiology \& Infectious Diseases, 29(1), 45-50. doi: https://doi.org/10.1007/s10096-009-0817-2

Henriques, A. F., Jenkins, R. E., \& Burton, N. F. (2011). The effect of manuka honey on the structure of Pseudomonas aeruginosa. European Journal of Clinical Microbiology \& Infectious Diseases, 30(2), 167-171. doi: https://doi.org/10.1007/s10096-010-1065-1 
Iradhati, A. H., \& Jufri, M. (2017). Formulation and physical stability test of Griseofulvin microemulsion gel. International Journal of Applied Pharmaceutics, 9(1), 7-10. doi: https://doi.org/10.22159/ijap.2017. v9s1.22_27

Irish, J., Blair, S., \& Carter, D. A. (2011). The antibacterial activity of honey derived from Australian flora. PLoS One, 6(3), 1-9. doi: https://doi.org/10.1371/journal.pone.0018229

Ismail, W. I. W. (2016). A review on beekeeping in malaysia history, importance and future direction. Journal of Sustainability Science and Management, 11(2), 70-80.

Jain, S., Rathod, N., Nagi, R., Sur, J., Laheji, A., Gupta, N., .. \& Prasad, S. (2016). Antibacterial effect of aloe vera gel against oral pathogens: An in-vitro study. Journal of Clinical and Diagnostic Research, 10(11), 41-44. doi: https://doi.org/10.7860/JCDR/2016/21450.8890

Jalil, M. A. A., Kasmuri, A. R., \& Hadi, H. (2017). Stingless bee honey, the natural wound healer: A review. Skin Pharmocology and Physiology, 30(2), 66-75. doi: https://doi.org/10.1159/000458416

Johnston, M., McBride, M., Dahiya, D., Owusu-apenten, R., \& Nigam, P. S. (2018). Antibacterial activity of Manuka honey and its components: An overview. AIMS Microbiology, 4(4), 655-664. doi: https://doi. org/10.3934/microbiol.2018.4.655

Jones, E. M., Cochrane, C. A., \& Percival, S. L. (2015). The effect of $\mathrm{pH}$ on the extracellular matrix and biofilms. Advances in Wound Care, 4(7), 431-439. doi: https://doi.org/10.1089/wound.2014.0538

Kaith, B. S., Sharma, R., \& Kalia, S. (2015). Guar gum based biodegradable, antibacterial and electrically conductive hydrogels. International Journal of Biological Macromolecules, 75(April), 266-275. doi: https://doi.org/10.1016/j.ijbiomac.2015.01.046

Kateel, R., Bhat, G., Baliga, S., Augustine, A. J., Ullal, S., \& Adhikari, P. (2018). Antibacterial action of tropical honey on various bacteria obtained from diabetic foot ulcer. Complementary Therapies in Clinical Practice, 30(1), 29-32. doi: https://doi.org/10.1016/j.ctcp.2017.11.001

Kim, C., Wilkins, K., Bowers, M., Wynn, C., \& Ndegwa, E. (2018). Influence of pH and temperature on growth characteristics of leading foodborne pathogens in a laboratory medium and select food beverages. Austin Food Sciences, 3(1), 1-8.

Lu, J., Turnbull, L., Burke, C. M., Liu, M., Carter, D. A., Schlothauer, R. C., .. \& Harry, E. J. (2014). Manukatype honeys can eradicate biofilms produced by Staphylococcus aureus strains with different biofilmforming abilities. Peer J, 2(326), 1-25. doi: https://doi.org/10.7717/peerj.326

Madiha, I. Y., Rukayadi, Y., \& Norhayati, H. (2017). Effects of extraction conditions on yield, total phenolic contents and antibacterial activity of methanolic Cinnamomum zeylanicum blume leaves extract. International Food Research Journal, 24, 779-786.

Majumdar, S., Roy, S., Gupta, R., \& Khatun, N. (2018). Strategy for improving skin permeation by using topical nanoparticulate gel of aloe vera and in-vivo evaluation using wistar rats. International Journal of Scientific and Research Publications, 8(2), 323-339.

Mohd-Aspar, M. A. S., \& Edros, R. Z. (2019). Antibacterial properties of kelulut, tualang and acacia honey against wound-infecting bacteria. Journal of Tropical Agricultural Science, 42(4), 1185-1208. 
Morshedi, A., \& Akbarian, M. (2014). Application of response surface methodology: Design of experiments and optimization: A mini review. Indian Journal of Fundamental and Applied Life Sciences, 4(S4), 2434-2439.

Moussa, A., Noureddine, D., Mohamed, H. S., \& Abdelmelek, M. (2012). Antibacterial activity of various honey types of Algeria against Staphylococcus aureus and Streptococcus pyogenes. Asian Pacific Journal of Tropical Medicine, 5(10), 773-776. doi: https://doi.org/10.1016/S1995-7645(12)60141-2

Mudgil, D., Barak, S., \& Khatkar, B. S. (2014). Guar gum: Processing, properties and food applications - A review. Journal of Food Scientist \& Technologists, 51(3), 409-418.

Mulye, S. P., Wadkar, K. A., \& Kondawar, M. S. (2014). Formulation development and evaluation of Indomethacin emulgel. Pelagia Research Library, 4(5), 31-45.

Negut, I., Grumezescu, V., \& Grumezescu, A. M. (2018). Treatment strategies for infected wounds. Molecules, 23(9), 1-23. doi: https://doi.org/10.3390/molecules23092392

Pande, V., Patel, S., Patil, V., \& Sonawane, R. (2014). Design expert assisted formulation of topical bioadhesive gel of Sertaconazole Nitrate. Advanced Pharmaceutical Bulletin, 4(2), 121-130. doi: https://doi. org/10.5681/apb.2014.019

Panther, D. J., \& Jacob, S. E. (2015). The importance of acidification in atopic eczema: An underexplored avenue for treatment. Journal of Clinical Medicine, 4(5), 970-978. doi: https://doi.org/10.3390/jcm4050970

Peacock, S. J., \& Paterson, G. K. (2015). Mechanisms of methicillin resistance in Staphylococcus aureus. Annual Review of Biochemistry, 84(1), 577-601. doi: https://doi.org/10.1146/annurev-biochem-060614-034516

Sanchez-Maldonado, A. F., Schieber, A., \& Ganzle, M. G. (2011). Structure-function relationships of the antibacterial activity of phenolic acids and their metabolism by lactic acid bacteria. Journal of Applied Microbiology, 111(5), 1176-1184. doi: https://doi.org/10.1111/j.1365-2672.2011.05141.x

Serra, R., Grande, R., Butrico, L., Rossi, A., Francesco, U., Settimio, ... \& Franciscis, S. de. (2015). Chronic wound infections: The role of Pseudomonas aeruginosa and Staphylococcus aureus. Expert Review of Anti-Infective Therapy, 13(5), 605-613. doi: https://doi.org/10.1586/14787210.2015.1023291

Shagana, J. A., \& Geetha, R. (2017). Comparative analysis of antimicrobial activity of black tea, green tea and white tea extracts on Streptococcus mutans by tube dilution method. Journal of Pharmaceutical Sciences and Research, 9(9), 1581-1582.

Shahzad, Y., Afreen, U., Shah, S. N. H., \& Hussain, T. (2012). Applying response surface methodology to optimize nimesulide permeation from topical formulation. Pharmaceutical Development and Technology, 18(6), 1391-1398. doi: https://doi.org/10.3109/10837450.2012.723721

Sharma, R., Kaith, B. S., Kalia, S., Pathania, D., Kumar, A., Sharma, N., ... \& Schauer, C. (2015). Biodegradable and conducting hydrogels based on Guar gum polysaccharide for antibacterial and dye removal applications. Journal of Environmental Management, 162, 37-45. doi: https://doi.org/10.1016/j. jenvman.2015.07.044

Shekar, P., Kumar, K. S., Jabasingh, S. A., Radhakrishnan, M., \& Balagurunathan, R. (2014). Optimization of medium components for antibacterial metabolite production from marine Streptomyces sp. PUA2 using response surface methodology. International Journal of Pharmacy and Pharmaceutical Sciences, 6(7), 6-11. 
Sherlock, O., Dolan, A., Athman, R., Power, A., Gethin, G., Cowman, S., \& Humphreys, H. (2010). Comparison of the antimicrobial activity of Ulmo honey from Chile and Manuka honey against methicillin-resistant Staphylococcus aureus, Escherichia coli and Pseudomonas aeruginosa. BMC Complementary and Alternative Medicine, 10(1), 1-5. doi: https://doi.org/10.1186/1472-6882-10-47

Singh, M. P., Nagori, B. P., Shaw, N. R., Tiwari, M., \& Jhanwar, B. (2013). Formulation development \& evaluation of topical gel formulations using different gelling agents and its comparison with marketed gel formulation. International Journal of Pharmaceutical Erudition, 3(3), 1-10.

Tan, H. T., Rahman, R. A., Gan, S. H., Halim, A. S., Hassan, S. A., Sulaiman, S. A., \& Kirnpal-Kaur, B. S. (2009). The antibacterial properties of Malaysian tualang honey against wound and enteric microorganisms in comparison to manuka honey. BMC Complementary and Alternative Medicine, 9(1), 1-8. doi: https:// doi.org/10.1186/1472-6882-9-34

Tuksitha, L., Chen, Y. S., Chen, Y., Wong, K., \& Peng, C. (2018). Antioxidant and antibacterial capacity of stingless bee honey from Borneo (Sarawak). Journal of Asia-Pacific Entomology, 21(2), 563-570. doi: https://doi.org/10.1016/j.aspen.2018.03.007

Wang, Y., Fang, X., An, F., Wang, G., \& Zhang, X. (2011). Improvement of antibiotic activity of Xenorhabdus bovienii by medium optimization using response surface methodology. Microbial Cell Factories, 10(1), 1-15. doi: https://doi.org/10.1186/1475-2859-10-98

World Health Organisation. (2018). WHO expert committee on specification for pharmaceutical preparations. Geneva, Switzerland. Retrieved July 20, 2020, from https://apps.who.int/iris/bitstream/hand le/10665/272452/9789241210195-eng.pdf?ua=1

Yaacob, M., Rajab, N. F., Shahar, S., \& Sharif, R. (2018). Stingless bee honey and its potential value: A systematic review. Food Research, 2(2), 124-133. doi: https://doi.org/10.26656/fr.2017.2(2).212

Yagoub, N. A. G. A., \& Nur, A. I. M. (2013). The influence of thermal treatment on physical properties of guar gum. International Journal of Innovations in Pharmaceutical Sciences, 2(6), 26-31.

Zhu, T., Mao, J., Cheng, Y., Liu, H., Lv, L., Ge, M., ... \& Lai, Y. (2019). Recent progress of polysaccharidebased hydrogel interfaces for wound healing and tissue engineering. Advanced Materials Interfaces, 6(17), 1-22. doi: https://doi.org/10.1002/admi.201900761 